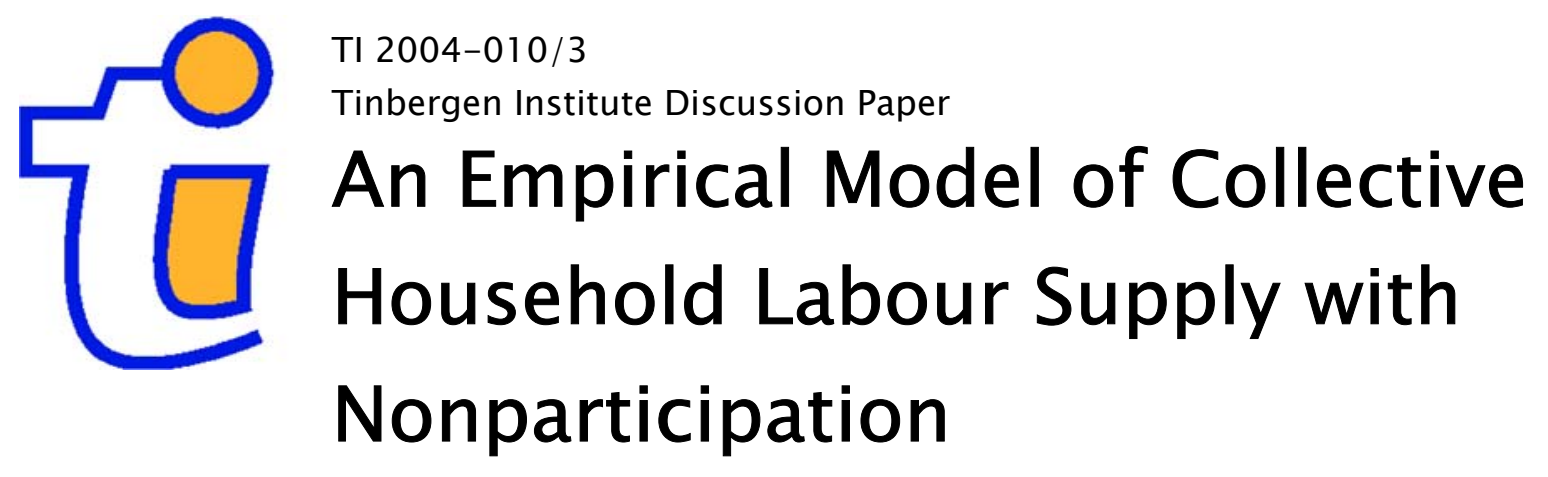

Hans G. Bloemen

Department of Economics, Vrije Universiteit Amsterdam, and Tinbergen Institute. 


\section{Tinbergen Institute}

The Tinbergen Institute is the institute for economic research of the Erasmus Universiteit Rotterdam, Universiteit van Amsterdam, and Vrije Universiteit Amsterdam.

Tinbergen Institute Amsterdam

Roetersstraat 31

1018 WB Amsterdam

The Netherlands

Tel.: $\quad+31(0) 205513500$

Fax: $\quad+31(0) 205513555$

Tinbergen Institute Rotterdam

Burg. Oudlaan 50

3062 PA Rotterdam

The Netherlands

Tel.: $\quad+31(0) 104088900$

Fax: $\quad+31(0) 104089031$

Please send questions and/or remarks of nonscientific nature to driessen@tinbergen.nl.

Most TI discussion papers can be downloaded at http://www.tinbergen.nl. 


\title{
AN EMPIRICAL MODEL OF COLLECTIVE HOUSEHOLD LABOUR SUPPLY WITH NONPARTICIPATION
}

\author{
by
}

\author{
Hans G. Bloemen ${ }^{1} 2$ \\ Department of Economics \\ Free University Amsterdam \\ De Boelelaan 1105 \\ $1081 \mathrm{HV}$ Amsterdam \\ The Netherlands
}

\begin{abstract}
January 2004
Keywords: Labour supply, Household behaviour, Collective model JEL code: J64
\end{abstract}

\begin{abstract}
We present a structural empirical model of collective household labour supply. Following recent developments in the literature on collective household labour supply our model allows for the nonparticipation decision, along with with the choice of working hours. We use the theoretical framework for the specification of a simultaneous model for hours, participation and wages of husband and wife. We discuss the problems of identification and statistical coherency that arise in the application of the collective household labour supply model. The model is estimated using a paneldata set of Dutch couples. The paneldata allow for the inclusion of random effects. The estimates allow us to check the underlying regularity conditions on individual preferences, and to obtain estimates of the sharing rule that governs the division of household income between husband and wife.
\end{abstract}

\footnotetext{
${ }^{1}$ We are greatly indebted to Statistics Netherlands for providing the data. We thank Martin Browning and participants of the CEMFI Madrid Microeconometrics Conference 2003 for their comments.

${ }^{2}$ email: hbloemen@feweb.vu.nl, phone: +31 20 4446037, fax: +31 204446005
} 


\section{Introduction}

The literature on collective models of household labour supply is growing. This has several reasons. Traditionally, the unitary model was used to explain the labour supply behaviour of households. The unitary model is the direct application of the neoclassical labour supply model for individual labour supply behaviour to the household as a decision unit. The unitary approach has been criticized for several reasons. One of the fundaments of micro-economic theory is that the individual is the decision making unit. The unitary model assumes that there exists a utility function for the household as a whole, and leaves the underlying preferences of the household members unspecified. The unitary model implies income pooling, which means that the incomes from the household members are aggregated and for the explanation of working hours of household members the source of the income does not matter. This implication places the income pooling restrictions on

the labour supply functions of individual household members, which are often found to be rejected in empirical work. Furthermore, the unitary model implies that the Slutsky conditions hold. Empirical studies often reject the Slutsky conditions for households with more than one member.

These considerations have led to the development of collective models of household labour supply as shown in Apps and Rees (1988) and Chiappori (1988, 1992). The collective model of household labour supply is explicitly based on individual preferences of the household members. A household welfare function is based on the utility functions of individuals as well as on the wage rates of individual household members. The interpretation behind this way of specifying household welfare is that there is a bargaining process between individual household members in which the wage rates influence the bargaining power of the members. Some approaches in the literature have explicitly modelled the underlying bargaining process between household members. Chiappori (1988) left the bargaining process unspecified and based his approach on the assumption of Pareto efficiency of the household decision process. If, in addition to the assumption of Pareto efficiency, the assumption is made that individual preferences are of the egoistic or caring type it is still possible to derive testable implications for the labour supply behaviour of 
individual household members. The household decision process can be respresented by a two-stage budgetting process: ${ }^{3}$ in the first stage the non-labour income of household members is divided between the members and in the second stage, conditional on this division, individuals make their labour supply decision. Chiappori (1988) shows that under the assumptions mentioned it is possible to nonparametrically recover (identify) the sharing rule of non-labour income between household members, up to an additive constant. The sharing rule is in general a function of the wage rates of individual household members and the total non-labour income. Thus, the result by Chiappori (1988) implies that it is in principle possible to identify the effect of an increase in individual wage rates and non-labour income on the sharing rule. Note that changes in any of these variables do not only affect labour supply behaviour in the conventional way through the household budget constraint but also by their effect on bargaining power. Because in the collective approach the wage rates and other income enter the household welfare function explicitly, the conventional Slutsky conditions do not hold.

Fortin and Lacroix (1997) empirically analyse the collective household labour supply model. For a Canadian cross section micro dataset of two-earner households, they estimate a collective household labour supply model with a flexible functional form. They carry out a complete set of tests of restrictions implied by the collective model and by the unitary model. However, as opposed to what is usual in the labour supply literature since the work by Heckman (1979), the specification of Fortin and Lacroix (1997) does not handle non-participation and corner solutions. The reason for this is that the modelling of the participation decision in the collective model is much more complicated than in the unitary model. Since the wage rate enters the labour supply function both directly, like in the unitary model, and indirectly, through the sharing rule, the derivation of a unique reservation wage is nontrivial and requires the placement of additional restrictions on the preferences of household members. However, for empirical work on

\footnotetext{
3 An underlying assumption for this two-stage procedure is that consumption of household members can be represented by a Hicks aggregate commodity and that there is no public good within the household. Children are often mentioned as an example of a public good that affects the division of time between household members. As a consquence, in empirical studies of collective household labour supply the sample is either restricted to couples without children (Blundell et al (2001)), or to couples without young children (Fortin and Lacroix (1997)).
} 
collective household labour supply the inclusion of nonparticipants is very important since restricting the sample to couples with working spouses may lead to selectivity bias in the estimates of the labour supply functions and the sharing rule.

Recently, the inclusion of nonparticipants in the collective labour supply model has been dealt with, both by Donni (2003) and by Blundell et al. (2001). Both studies show that the reservation wage does not follow directy from the model but needs to be postulated. They both present (comparable) restrictions which ensure the uniqueness of the reservation wage. Donni (2003) leaves the hours choice of husband and wife unrestricted: both household members can choose not to work or any positive amount of working hours. Blundell et al. (2001) assume that men can only choose to work 40 hours a week or choose not to work at all. Donni (2003) shows that the identification result by Chiappori (1988) for the sharing rule can be extended to the case in which one of the household members does not participate. Donni (2003) shows that in empirical applications the nonparticipation may be incorporated by means of a switching regression model.

Blundell et al. (2001) derive additional restrictions by simultaneously incorporating the Chiappori (1988) approach and the reservation wage equation for males. To apply their their approach empirically, though, the explicit existence of the reservation wage for males is required, which may limit the choice of functional form.

Blundell et al. (2001) also adress the identification of an empirical model of collective household labour supply with the choice of nonparticipation. They derive explicit rules for the identification of the effects of the covariates of the wage equation, the sharing rule and the participation equation. They show how the restrictions of the collective household labour supply model can be translated into parameter restrictions in a simple functional form for the labour supply function of women.

For empirical purposes, the approaches by both Donni (2003) and Blundell et al. (2001) suggest the specification of a switching regression model. In their models the emphasis is on the choice of working hours by one partner, conditional on the participation decision by the other: e.g. the equation for the wife's working hours is different, depending on the husband's labour market state. Blundell et al. (2001) include an 
empirical application of their approach which abstracts from variation in male working hours. They motivate this approach by pointing at the fact that the majority of working males is working around 40 hours a week in the UK. In our Dutch datasete a considerable minority of $30 \%$ of the Dutch males works outside the full-time range of 38 to 42 hours a week, and it is likely that especially the working hours outside the full-time range may be interrelated with the choice of working hours by the wifes.

Empirical applications of the collective household labour supply model are still scarce. Data requirements, which include the availability of information on labour supply and wages for both spouses as well as information on the household's nonlabour income, preferably for childless couples, certainly contribute to this scarcity. In this study we expand on the empirical literature of collective household labour supply. We specify a model that allows for nonparticipation. Moreover, our model includes information on working hours of both husband and wife. An additional complication that arises in modelling both the hours and the participation decision is the problem of statistical coherency. We derive parameter restrictions that are sufficient for the coherency of our model. ${ }^{4}$ The study by Fortin and Lacroix (1997) shows how difficult it is to obtain precise estimates of the sharing rule and the individual preferences from the reduced form labour supply functions. Therefore we pay specific care to the specification of the sharing rule and include a measure for the relative wages to represent the relative bargaining power of the partners. ${ }^{5}$ develop the pecification As opposed to Fortin and Lacroix (1997), the emphasis is not on testing the unitary versus the collective model, but much more on the aim to recover the parameters of the sharing rule and individual preferences. Nevertheless we also provide a formal test of the symmetry restrictions that the unitary model imposes on the specification.

The model that we specify contains equations for the working hours of husband and

\footnotetext{
${ }^{4}$ Note that the problem if statistical coherency does not arise in a switching regression framework in which the analysis is restricted to the hours of one partner, while only information on participation of the other partner is used.

${ }^{5}$ Chiappori, Fortin and Lacroix (2002) extend on the specification of the sharing rule by analyzing the impact of distribution factors like the sex ratio in the marriage market and the rules of the divorce legislation. Thus, they include additional identiying information in the sharing rule. They analyze couples in which both spouses work.
} 
wife and for the wages of both spouses. We address the identification problem that arises due to the underlying structure of the collective approach. In the econometric specification we allow for the endogeneity of wage rates and for correlation between working hours of husband and wife due to unobserved heterogeneity. In the estimation, we use simulation methods to integrate over unobserved wage rates: we estimate the parameters of the hours and participation equations and the wage distribution simultaneously by simulated maximum likelihood (SML).

We use data from the Dutch Socio Economic Panel for the years 1990-1997. This is a panel survey among Dutch households. We select a panel data set of Dutch couples who are living without children. The data contains detailed information about the labour market status, working hours, wage rates and various background characteristics of both husband and wife. We exploit the panel feature of the data by allowing for random effects in the labour supply and wage equations. By estimating both a model variant without random effects and a specification in which we include random effects, we gain insight in the robustness of the model results.

The estimation of several model variants allows us to check whether underlying regularity conditions for individual preferences are satisfied. We obtain estimates of the sharing rule, which provides insight into the division of household income between husband and wife and into the labour supply behaviour of husband and wife.

In section 2 we describe the collective model of labour supply which provides the necessary background for the purpose of specifying an empirical variant of the model. In section 3 we specify our empirical model. Here we address problems of identification and statistical coherency. Section 4 contains a description of the available data. In section 5 we present the results of estimation. Section 6 concludes.

\section{The collective model: theoretical framework}

In this section we describe the collective model of labour supply. We formulate the model and discuss the identification results of the sharing rule, as derived by Chiappori $(1988,1992)$, and the extended results that allow for corner solutions by Blundell et al. 
(2001) and Donni (2003).

In the sequel we consider the labour supply decision of a household, consisting of husband and wife. We denote the working hours, consumption and the wage rate of the husband and wife by $\left(h_{m}, C_{m}, w_{m}\right)$ and $\left(h_{f}, C_{f}, w_{f}\right)$, respectively, while $y$ denotes the household's non-labour income. The identification results of the sharing rule require household preferences to be of the egoistic (or caring) type. Moreover, the sharing rule representation of the collective labour supply problem requires the absence of public goods within the household. Since the presence of children is likely to have the largest influence on the division of time between household members, in empirical applications of the collective labour supply model the analysis is usually restricted to childless couples. In this section we assume preferences to be egoistic. The utility level of household member $i$, working $h_{i}$ hours and consuming $C_{i}$, is denoted by $u^{i}\left(1-h_{i}, C_{i}\right)$. We assume that the utility function satisfies the usual regularity conditions.

The collective approach assumes that households only take Pareto efficient decisions. Formally, for any combination of wages and nonlabour income $\left(w_{m}, w_{f}, y\right)$ there exists a utility level $\bar{u}^{m}\left(w_{m}, w_{f}, y\right)$ such that $\left(h_{m}, C_{m}, h_{f}, C_{f}\right)$ is the solution to the following decision problem: 6

$$
\begin{aligned}
& \max _{h_{m}, C_{m}, h_{f}, C_{f}} u^{f}\left(1-h_{f}, C_{f}\right) \\
& u^{m}\left(1-h_{m}, C_{m}\right) \geq \bar{u}^{m}\left(w_{m}, w_{f}, y\right) \\
& C_{m}+C_{f}=w_{m} h_{m}+w_{f} h_{f}+y \\
& 0 \leq h_{m}, h_{f} \leq 1
\end{aligned}
$$

The utility level $\bar{u}^{m}\left(w_{m}, w_{f}, y\right)$ can be interpreted as the outcome of a bargaining process between husband and wife, and the wage rates of husband and wife may influence the bargaining power of the household members. The bargaining process itself is left unspecified. An alternative representation of (1) follows from applying the second fundamental theorem of welfare economics. A pair of labour supply functions $\left(h_{m}^{*}, h_{f}^{*}\right)$ is collectively rational (i.e. satisfies $(1))$ if there exists a combination $\left(\bar{C}^{m}, \bar{C}^{f}\right)$ and a pair of functions

\footnotetext{
${ }^{6}$ Various alternative representations of the decision problem are possible. For example, the objective function can be written as a weighted average of the utility functions of husband and wife, with weights that depend on $\left(w_{m}, w_{f}, y\right)$. This can be seen directly by applying Kuhn-Tucker to (1). See Vermeulen (2002) for an overview.
} 
$\left(\rho^{m}, \rho^{f}\right)$ such that $\left(h_{i}^{*}, \bar{C}_{i}\right)$ is a solution to

$$
\begin{aligned}
& \max _{h_{i}, C_{i}} u^{i}\left(1-h_{i}, C_{i}\right) \\
& \text { subject to } C_{i}=w_{i} h_{i}+\rho^{i}, i=m, f \\
& \text { with } \rho^{m}+\rho^{f}=y
\end{aligned}
$$

Thus, the collective rational household labour supply decision can be represented by a two-stage budgeting problem. In the first stage the share $\rho^{i}, i=m, f$, of non-labour income $y$ of each household member is determined. The share depends on the bargaining power of the household members which in turn depends on the wages of the members, and we may denote $\rho^{m}=\rho\left(w_{m}, w_{f}, y\right)$ and $\rho^{f}=y-\rho\left(w_{m}, w_{f}, y\right)$. Note that $\rho$ is not restricted to be positive so transfers from the one household member to the other are possible.

The decision problem (2) is the basis for deriving the restrictions that the collective approach imposes on the labour supply function. Let $H^{i}\left(w_{i}, \rho^{i}\right)$ denote the 'structural' labour supply function conditional on $\rho^{i}$ that follows from solving $(2)$, and let $h_{i}^{*}\left(w_{i}, w_{j}, y\right)$ denote the 'reduced form' labour supply function. Then it follows that

$$
\begin{aligned}
& h_{m}^{*}\left(w_{m}, w_{f}, y\right)=H^{m}\left(w_{m}, \rho\left(w_{m}, w_{f}, y\right)\right) \\
& h_{f}^{*}\left(w_{f}, w_{m}, y\right)=H^{f}\left(w_{f}, y-\rho\left(w_{m}, w_{f}, y\right)\right)
\end{aligned}
$$

Thus, from (3) it follows, among other things, that the wage rate of the other household member enters the labour supply function through the sharing rule. The wage rate of the husband influences the labour supply decision of the wife both because of its effect on total household income and because it influences the sharing rule by the bargaining power.

The relationship in (3) is the basis for the identification result of Chiappori (1988, 1992) which reads that, given information on working hours, wages, and non-labour income of both household members, in the absence of corner solutions the sharing rule $\rho\left(w_{m}, w_{f}, y\right)$ can be recovered up to an additive constant. This means that we are able to recover marginal effects of the respective wage rates of husband and wife on the sharing rule, which are potentially important from a policy point of view. The sharing rule can be recovered by taking first and second order partial differentials of (3) which constitutes a system of differential equations from which the sharing rule can be solved. 
The approach described so far does not account for the presence of corner solutions. In empirical models of collective labour supply corner solutions are usually ignored by restricting the sample to working couples. In contrast, in empirical models of individual labour supply the option of choosing zero working hours usually is accounted for to prevent selectivity bias. In models of individual labour supply, the reservation wage follows naturally from the model as the wage rate at which optimal working hours are exactly equal to zero, or, equivalently, as the wage rate that is equal to the marginal rate of substitution between consumption and labour supply, evaluated at zero working hours. In collective models of labour supply the reservation wage does not follow naturally from the model as e.g. the wage of the male affects male labour supply both directly, in the same way as in individual models of labour supply, and indirectly, through the sharing rule, and moreover, it affects female labour supply by the sharing rule. Both Donni (2003) and Blundell et al. (2001) address this problem in a different way. Donni (2003) takes as point of departure the model outlined above which assumes that working hours of husband and wife both vary continuously. Blundell et al. (2001) assume that the hours of the wife vary continuously, whereas the weekly working hours of the husband are restricted to either zero or fourty. Since our empirical model is based on the framework by Donni (2003), we will give an outline the result by Donni (2003).

First Donni $(2003)$ defines the function $\omega^{i}\left(w_{m}, w_{f}, y\right)$ by the marginal rate of subtitution between leisure and consumption of household member $i$ :

$$
\omega^{i}\left(w_{m}, w_{f}, y\right)=-\frac{u_{h}^{i}\left(1, \rho^{i}\left(w_{m}, w_{f}, y\right)\right)}{u_{c}^{i}\left(1, \rho^{i}\left(w_{m}, w_{f}, y\right)\right)}
$$

In (4) the subscripts $h$ and $c$ indicate partial derivatives with respect to labour supply and consumption, respectively. Now the reservation wage rate for household member $i$ is defined as the wage $w_{i}$ for which $w_{i}=\omega^{i}\left(w_{m}, w_{f}, y\right)$. An additional assumption needs to be made to ensure uniqueness of the reservation wage rate. To this purpose Donni (2003) formulates assumption R1:

For any $\left(w_{m}^{*}, w_{f}^{*}, y\right)$ and $\left(\tilde{w}_{m}, \tilde{w}_{f}, y\right)$ preferences and the sharing rule are such that

$$
\max _{i=m, f}\left(\left|\omega^{i}\left(w_{m}^{*}, w_{f}^{*}, y\right)-\omega^{i}\left(\tilde{w}_{m}, \tilde{w}_{f}, y\right)\right|\right) \leq \max _{i=m, f}\left(\left|w_{i}^{*}-\tilde{w}_{i}\right|\right)
$$


Intuitively (5) is close to saying that the marginal rate of substitution between labour supply and consumption at zero working hours rises less than proportional with the wage. Condition (5) ensures uniqueness of the reservation wage in two senses. First, there exists a unique pair of reservation wages $\hat{w}_{m}(y)$ and $\hat{w}_{f}(y)$ such that both household members are indifferent between working and not. Second, for household member $i$ there exists a reservation wage $\gamma^{i}\left(w_{j}, y\right)$, given the wage $w_{j}$ of the other household member, such that household member $i$ prefers to work if $w_{i}>\gamma^{i}\left(w_{j}, y\right)$.

Both Donni (2003) and Blundell et al. (2001) provide a proof of the identification of the sharing rule (up to an additive constant) by extending the identification result by Chiappori (1988). Both show that the original differential equations derived from (3) are, by continuity, also satisfied in the limit on the participation frontier on which one partner works and the other does not (formally defined by e.g $w_{m}=\gamma^{m}\left(w_{f}, y\right)$ if the wife works) and they show that as an additional condition for identification this boundary condition should be identifiable separately from (i.e. should be nontangent to) the participation frontier itself.

\section{Specification}

\subsection{Preferences, labour supply and the sharing rule}

As a point of departure for our empirical specification we take the utility function from Hausman and Ruud (1984). The utility function of household member $j, j=m, f$ reads

$$
u^{j}(h, c)=m^{*} \exp \left\{\frac{\beta_{j}}{\gamma_{j}}\left(h-\delta_{j}-\beta_{j} m^{*}\right)\right\}
$$

with

$$
m^{*}=\frac{\gamma_{j}}{\beta_{j}^{2}}\left[1-\left\{1+\frac{\beta_{j}^{2}}{\gamma}\left[\frac{\left(h-\delta_{j}\right)^{2}}{\gamma_{j}}-2\left(c+\theta_{j}\right)\right]\right\}^{\frac{1}{2}}\right]
$$

Maximization of (6) subject to a linear budget constraint leads to the labour supply function

$$
H^{j}\left(w_{j}, y_{j}\right)=\delta_{j}+\mu_{j}^{*} \beta_{j}+w_{j} \gamma_{j}
$$

with

$$
\mu_{j}^{*}=\theta_{j}+y_{j}+\delta_{j} w_{j}+\frac{1}{2} \gamma_{j} w_{j}^{2}, j=m, f
$$


Concavity of the cost function of the dual problem requires $\mu_{j}^{*}<\gamma_{j} / \beta_{j}^{2}$. Furthermore, labour supply is nonincreasing in nonlabour income $y$ if $\beta_{j}<0$ and $\gamma_{j}>0$. The labour supply function in (8) and (9) can be written more compactly as

$$
H^{j}\left(w_{j}, y_{j}\right)=\alpha_{1}^{j}+\alpha_{2}^{j} y_{j}+\alpha_{3}^{j} w_{j}+\alpha_{4}^{j} w_{j}^{2}, j=m, f
$$

with $\alpha_{1}^{j}=\delta_{j}+\beta_{j} \theta_{j} ; \alpha_{2}^{j}=\beta_{j} ; \alpha_{3}^{j}=\gamma_{j}+\beta_{j} \delta_{j} ; \alpha_{4}^{j}=\beta_{j} \gamma_{j} / 2$ Note that $\beta_{j}<0$ and $\gamma_{j}>0$ imply that $\alpha_{2}^{j}<0$ and $\alpha_{4}^{j}<0$.

Now we assume that the sharing rule $\rho\left(w_{m}, w_{f}, y\right)$ has the following form:

$$
\rho\left(w_{m}, w_{f}, y\right)=k_{1}+k_{2} w_{m}+k_{3} w_{f}+k_{4} \frac{w_{m}}{w_{m}+w_{f}}+k_{5} y+k_{6} \frac{w_{m}}{w_{m}+w_{f}} y
$$

Inserting the sharing rule (11) in the 'structural' labour supply functions (10) (with $y_{m}=\rho$ and $y_{f}=y-\rho$ ), results in the 'reduced form' labour supply functions:

$$
\begin{gathered}
h_{m}\left(w_{m}, w_{f}, y\right)=a_{1}+a_{2} w_{m}+a_{3} w_{f}+a_{4} \frac{w_{m}}{w_{m}+w_{f}}+a_{5} w_{m}^{2}+a_{6} y+a_{7} \frac{w_{m}}{w_{m}+w_{f}} y \\
h_{f}\left(w_{m}, w_{f}, y\right)=b_{1}+b_{2} w_{m}+b_{3} w_{f}+b_{4} \frac{w_{m}}{w_{m}+w_{f}}+b_{5} w_{f}^{2}+b_{6} y+b_{7} \frac{w_{m}}{w_{m}+w_{f}} y
\end{gathered}
$$

Note that we include the husband's wage rate as a fraction of the sum of the wage rates of both spouses. This fraction represents the role of the relative bargaining power of husband and wife and the relative marginal effects of working hours on total household income. Note that if leisure is a normal good for both husband and wife (i.e. $\left.\alpha_{2}^{j}<0, j=m, f\right)$ the parameters $a_{4}$ and $b_{4}$ in the 'reduced form' labour supply function (12) should have the opposite sign. In general, this is a property that holds for all variables that enter the sharing rule but not the 'structural' labour supply functions. For this reason it is important that terms that appear in the sharing rule but not in the "structural' labour supply functions can be interptreted as variables that represent the relative power, or relative wages, of husband and wife. ${ }^{7}$ To allow for further flexibility of the sharing rule, we also include a cross effect of the fraction of the husband's wage rate and non-labour income. Chiappori, Fortin and Lacroix (2002) extend on the identification of the sharing rule by including addtional information that have the interpretation of "distribution factors", like the sex ratio in the marriage market and the rule of the divorce

\footnotetext{
${ }^{7}$ For instance, the adding of polynomials in wage rates or non-labour income (for the sake of flexibility) as additional terms in the sharing rule that do not appear in the structural labour supply function, is very unlikely to lead to coefficients of the opposite sign in the reduced form labour supply functions.
} 
legislation. However, they restrict their analysis to couples with working spouses. In our analysis, the use of information on couples in which one spouse $^{8}$ does not participate leads to additional identifying information compared to the case in which both spouses are working, since the labour market status may influence the relative bargaining power of spouses.

The parameters of the sharing rule $k_{l}, l=2, \ldots, 6$ can be identified from the parameters of the labour supply functions (12):

$$
\begin{gathered}
k_{2}=b_{2} a_{4} / \Delta, k_{3}=b_{4} a_{3} / \Delta, k_{4}=b_{4} a_{4} / \Delta, k_{5}=b_{4} a_{6} / \Delta \\
k_{6}=b_{4} a_{7} / \Delta, \Delta=b_{4} a_{6}-a_{4} b_{6}
\end{gathered}
$$

A cross equation constraint that follows from the structure of the model is $b_{7} a_{4}=a_{7} b_{4}$. The latter restriction can be tested in the empirical application. The parameters in (10) can be expressed in terms of the parameters in (12) as $\alpha_{2}^{m}=\Delta / b_{4} ; \alpha_{3}^{m}=a_{2}-$ $b_{2} a_{4} / b_{4} ; \alpha_{4}^{m}=a_{5} ; \alpha_{2}^{f}=-\Delta / a_{4} ; \alpha_{3}^{f}=b_{3}-b_{4} a_{3} / a_{4} ; \alpha_{4}^{f}=b_{5}$. An additional requirement for identification of the sharing rules is that $a_{6} \neq b_{6}, a_{7} \neq b_{7}, a_{4} \neq b_{4}$.

Note that it is potentially important to allow for backward bending of the 'structural' labour supply functions. For instance, an increase in the husband's wage rate has a direct effect on his supply of labour, by the coefficients of the labour supply function (10) and an indirect effect, that runs through the sharing rule (11). Not allowing for backward bending will bias the estimates of the effect that runs through the sharing rule.

Previous empirical work on the collective labour supply model (see, for instance, Fortin and Lacroix (1997)) shows that it is notoriously difficult to obtain precise point estimates of the parameters of the sharing rule and the underlying preferences. The above expressions for the sharing rule parameters $k_{j}$ in terms of the reduced labour supply parameters $a_{j}$ and $b_{j}$ make clear why this is the case. The parameters $a_{j}$ and $b_{j}$ are the parameters that directly measure the effects of the variables on labour supply. One sharing rule parameter $k_{j}$ depends on five reduced form labour supply parameters. It is particularly important that the expression $\Delta=b_{4} a_{6}-a_{4} b_{6}$ is estimated precisely. Even if the separate coefficients appearing in this expression are estimated significantly, $\Delta$ may show up insignificant, especially if $b_{4} a_{6}$ and $a_{4} b_{6}$ have the same sign. This once

\footnotetext{
${ }^{8}$ In the estimation we also use observations for couples in which both spouses are not working. The sharing rule for this case in not identified.
} 
again shows that the variables entering the sharing rule should be chosen with some care and that one may easily overparameterize the model such that the point estimates of the coefficients of the sharing rule show up insignificant, even if the reduced form labour supply parameters are estimated precisely.

For future reference we introduce the vector notation $\phi_{m}=\left(a_{1}, a_{2}, a_{3}, a_{4}, a_{5}, 0, a_{6}, a_{7}\right)^{\prime}$, $\phi_{f}=\left(b_{1}, b_{2}, b_{3}, b_{4}, 0, b_{5}, b_{6}, b_{7}\right)^{\prime}$ and $W=\left(1, w_{m}, w_{f}, w_{m} /\left(w_{m}+w_{f}\right), w_{m}^{2}, w_{f}^{2}, y, w_{m} y /\left(w_{m}+w_{f}\right)\right)^{\prime}$.

The relations in (13) between the labour supply parameters in (12) and the parameters of the sharing rule in (11) hold for the case in which both husband and wife are working and can choose any number of working hours. The analysis by Donni (2003) shows how the labour supply model can be extended to the case in which the husband works and the wife does not. Donni (2003) proposes a switching regression model for labour supply of the husband. If the wife does not work, male labour supply becomes:

$$
h_{m}\left(w_{m}, w_{f}, y\right)=\Phi_{m}^{\prime} W
$$

The underlying reason for this 'switch' is a difference in the sharing rule due to the different female labour market state. If the wife works, her wage income actually affects the total household income and consequently influences the sharing rule. Apart from that, the wife's wage rate affects the sharing rule due to her bargaining power. If the wife does not work, only the effect of the wife's (potential) wage rate on the bargaining power remains. The identification results and continuity assumptions by Donni (2003) for the case in which the wife does not work show that if the wife is at the participation frontier, male labour supply when the wife does not work is a limit case of male labour supply when the wife does work.

The following relation between the parameters $\Phi_{m}$ of male labour supply when the wife does not work and $\phi_{m}$ of male labour supply when the wife works may hold:

$$
\Phi_{m}^{\prime} W=\phi_{m}^{\prime} W+s\left(\phi_{f}^{\prime} W\right)
$$

In (15) $s$ represents a parameter. Restriction (15) implies that if female labour supply $\phi_{m}^{\prime} W$ is equal to zero (i.e. the wife is on the participation frontier) the two regressions 
are the same. The sharing rule for the case in which the wife does not work may be represented by

$$
\rho\left(w_{m}, w_{f}, y\right)=K^{\prime} W
$$

Letting $k^{\prime} Z$ represent the vector notation of the right hand side of (11), we may on similar arguments impose the following restriction

$$
K^{\prime} W=k^{\prime} W+r\left(\phi_{f}^{\prime} W\right)
$$

In (17) $r$ is a parameter. The following relation between the parameters $s$ and $r$ from (15) and (17) is implied by the structure of the collective setting:

$$
r=\frac{s b_{4}}{\Delta}
$$

In a similar way, we may introduce a switching regression for the wife if the husband does not work. Let the wife's labour supply function in this case be presented by

$$
h_{f}\left(w_{m}, w_{f}, y\right)=\Phi_{f}^{\prime} W
$$

and let the sharing rule in this case be

$$
\rho\left(w_{m}, w_{f}, y\right)=\tilde{K}^{\prime} W
$$

The equivalents of (15) and (17) become

$$
\Phi_{f}^{\prime} W=\phi_{f}^{\prime} W+S\left(\phi_{m}^{\prime} W\right)
$$

and

$$
\tilde{K}^{\prime} W=k^{\prime} W+R\left(\phi_{f}^{\prime} Z\right)
$$

and the collective framework implies the following restriction between the parameters $R$ and $S$ :

$$
R=\frac{S a_{4}}{\Delta}
$$




\subsection{Unitary restrictions}

The unitary model imposes various restrictions on the labour supply functions (12). We stress that the purpose of this study is not to provide an exhaustive test of the unitary model. Before we have motivated the empirical specification of (12) from which we may empirically identify not only the reduced form parameters but also the structural parameters of the sharing rule and the individual labour supply functions. However, a discussion of the unitary restrictions provides additional insights into our specification.

The most well known implication of the unitary model isn the pooling hypothesis. For testing the pooling restrictions in the context of a labour supply model we must be able to split up non-labour income in two parts and assign the different parts to husband and wive (see, for instance, Fortin and Lacroix (1997)). In the data it will typically be hard to assign one of the spouses as the original owner of the income source. For this reason we abstain from testing the pooling restrictions for the moment.

Other restrictions imposed by the unitary model concern the Slutsky matrix. Defining $S_{i j}, i, j=m, f$ as the element $(i j)$ of the matrix, we have $S_{i j}=\partial h_{i} / \partial w_{j}-h_{j} \partial h_{i} / \partial y$. The unitary model imposes (i) Symmetry: $S_{m f}=S_{f m}$; (ii) non-negativity of compensated own wage effects: $S_{i i}>0, i=m, f$; (iii) non-negativity of the determinant of the Slutsky matrix: $S_{m m} S_{f f}-S_{m f}^{2}>0$.

Symmetry can be imposed on (12) by imposing the following 9 parameter restrictions: $a_{6} b_{j}=a_{j} b_{6}, j=2,3, a_{j}=0, b_{j}=0, j=4,5,7, a_{3}-b_{1} a_{6}=b_{2}-a_{1} b_{6}$. These restrictions may be imposed in the estimation of the model and can subsequently be tested by the likelihood ratio test. Note that there are some exclusion restrictions among these symmetry restrictions. First, the male wage rate as a fraction of the wage rates of both partners disappears. Since this fraction represents the bargaining power of the two partners in the sharing rule, which is a concept that does not appear in the unitary model, it is appealing that it is excluded once the unitary model is imposed. This also illustrates the importance of the inclusion of this variable for recovering the sharing rule. Second, the parameters that represent the squared wage rates due to backward bending disappear as well since the own wage rate squared appears only in the own labour 
supply function. This is due to the fact that the collective model is based on individual preferences, whereas between labour supply functions that stem from a unitary model such a difference is not possible. ${ }^{9}$

The validity of the remaining 2 restrictions depend on the values of wage rates and non-labour income and therefore varies by observation. We can check whether these conditions are satisfied for all observations after having estimated the model.

Note that in the collective model Slutsky conditions apply to the individual labour supply function (10). More specific, the Slutsky conditions imply $\partial H_{j} / \partial w_{j}-$ $h_{j} \partial H_{j} / \partial \rho_{j} \geq 0, j=m, f$. This holds true if $\alpha_{3}^{j}+2 \alpha_{4}^{j} w_{j}-h_{j} \alpha_{2}^{j}>0, j=m, f$. Thus if the effect of the wage on the individual labour supply function is dominantly positive (i.e. the backward bending effect is not too strong) and if leisure is a normal good we may expect that the Slutsky condition holds.

\subsection{Heterogeneity and coherency}

\section{Introducing heterogeneity}

So far we abstained from the introduction of observed and unobserved heterogeneity. The identification results by Donni (2003) are derived in the absence of heterogeneity. The theoretical framework by Blundell et al. (2001) does not incorporate heterogeneity, but in their empirical model they include additive observed and unobserved heterogeneity in the labour supply functions and the sharing rule. The additive form of the heterogeneity ensures that the derived results for the identification of the sharing rule remain valid. Blundell et al. (2001) discuss the additional complications that arise in the identification of coefficients of observed heterogeneity. A particular problem that arises is the lack of suitable exclusion restrictions, due to the interrelationship between labour supply and participation of husband and wife. They derive that under certain conditions the female labour supply function and the mean (log) wage of husband and wife can be identified up to unknown additive constants. ${ }^{10}$

\footnotetext{
9 As an alternative we may included the wage rates squared in both labour supply functions in order to nest this implication of the unitary model in the specfication, but this will come at the loss of identifying power. We have also run this variant and the results of this are discussed in section 5 .

10 I.e. estimates of additive constants are identified solely by functional form.
} 
Let $z_{m}$ and $z_{f}$ be vectors of observed characteristics affecting male and female preferences, respectively. Let $\nu_{j}, j=m, f$ denote unobserved heterogeneity. It can easily be checked that in order to obtain labour supply functions that are additive in observed and unobserved heterogeneity, we may specify the preference parameter $\theta_{j}$ in (9) as a linear combination of observed and unobserved heterogeneity. Blundell et al. (2001) argue that it is reasonable to assume that the heterogeneity in preferences of both husband and wife enter the sharing rule as well. Thus, we may extend (12) by writing

$$
h_{j}=\phi_{j}^{\prime} W+\zeta_{j}^{\prime} z+\nu_{j}, j=m, f
$$

The analysis so far assumed the observability of wages, even if someone is not working. For the empirical analysis, we specify the following wage equation:

$$
\ln w_{j}=\eta_{j}^{\prime} x_{j}+u_{j}, j=m, f
$$

Combining (24) with (15), (21) and (25) and denoting $d_{j}=1$ if household member $j$ participates, $d_{j}=0$ otherwise, we may summarize the conditions for participation, conditional on the wages, as

$$
\begin{aligned}
& d_{j}=\iota\left(h_{j}^{*}>0\right), j=m, f \\
& h_{f}^{*}=\phi_{f}^{\prime} W+\zeta_{f}^{\prime} z+\nu_{f}+\left(1-d_{m}\right) S\left(\phi_{m}^{\prime} W+\zeta_{m}^{\prime} z+\nu_{m}\right) \\
& h_{m}^{*}=\phi_{m}^{\prime} W+\zeta_{m}^{\prime} z+\nu_{m}+\left(1-d_{f}\right) s\left(\phi_{f}^{\prime} W+\zeta_{f}^{\prime} z+\nu_{f}\right)
\end{aligned}
$$

The equations for male and female working hours become:

$$
\begin{array}{ccc}
h_{j}=h_{j}^{*} & \text { if } & h_{j}^{*}>0, j=m, f \\
h_{j}=0 & & \text { otherwise }
\end{array}
$$

\section{Coherency of the model}

In the estimation of the model an additional complication arises as the system (26) is not necessarily coherent: without any further restrictions, for given values of $\left(W, z, \nu_{m}, \nu_{f}\right)$ the model in (26) may generate multiple outcomes for the participation of husband and wife in a household. In other words, the conditions for e.g. $\left(d_{m}=0, d_{f}=1\right)$ and for $\left(d_{m}=1, d_{f}=0\right)$ are not exclusive. As a result the probabilities of the four combinations of male and female participation would add up to an amount larger than 1. In general, imposing coherency in a model like this is either quite complicated (see, for instance, 
Kooreman (1994)) or greatly reduces the generality of the model (see Heckman (1978)). For the system (26), however, it can be shown that, apart from the trivial case $S s=0$, coherency holds for more combinations of $s$ and $S$. In appendix $\mathrm{A}$ we show that the model is coherent for all combinations of $s$ and $S$ for which $|s S|<1$.

\section{Estimation by (simulated) maximum likelihood}

Now the complete model is defined by equations (25)-(27). We will estimate the model parameters by maximum likelihood. The construction of the likelihood function consists of the following steps. First, the density of $\left(\nu_{m}, \nu_{f}, u_{m}, u_{f}\right)$ is specified. Next, (27) can be used to derive the likelihood contributions for various observations, conditional on the wages $w_{m}$ and $w_{f}$. Third, the density function of wages can be formed to complete the likelihood contribution. For observations without observed values for the wages, which includes the nonparticipating men and women, we can integrate over wages to complete the likelihood contribution. In the application we employ the smooth simulated maximum likelihood method (see Börsch-Supan and Hajivassiliou (1993)) with 60 replications to integrate over wages. The coherency constraint $|s S|<1$ will be imposed in the estimation of the model.

Throughout we will assume that the errors of the wage equations and the labour supply equations follow a joint normal distribution:

$$
\left(\begin{array}{c}
\nu_{m} \\
\nu_{f} \\
u_{m} \\
u_{f}
\end{array}\right) \sim N\left(\left(\begin{array}{l}
0 \\
0 \\
0 \\
0
\end{array}\right),\left(\begin{array}{cccc}
\sigma_{m}^{2} & \sigma_{m f} & \sigma_{m u} & 0 \\
\sigma_{m f} & \sigma_{f}^{2} & 0 & \sigma_{f u} \\
\sigma_{m u} & 0 & \tau_{m}^{2} & \tau_{m f} \\
0 & \sigma_{f u} & \tau_{m f} & \tau_{f}^{2}
\end{array}\right)\right)
$$

Throughout we assume independence between different households. Note that we allow for nonzero correlation between the errors of the labour supply functions (parameter $\left.\sigma_{m f}\right)$. Thus we allow for common, household specific, unobserved characteristics in, say, preferences. Furthermore, we allow for correlation between the male (female) labour supply equation and the male (female) wage rates to correct for possible selectivity bias for the fact that wages are only observed for participants. Note that we restricted the correlation between the errors of the husband's (wife's) labour supply equation and the wife's (husband's) wage equation to zero. Finally, we allow for nonzero correlation between 
the errors of the wages of husband and wife. This may capture common unobserved components in the wages of both partners, like for instance the effect of region.

\section{A switching regression variant}

The model formulated in (27) and (26) may be estimated with information on both participation and working hours of husband and wife. In this respect, the model expands on the work by Blundell et al. (2001) and Donni (2003): both approaches suggest to model collective labour supply by a switching regression model, using information on both working hours and participation of one partner and only on participation of the other partner. Thus, variation in working hours by the other partner is ignored. A switching regression variant (for hours and participation of the wife and for participation of the husband) of our model reads

$$
\begin{aligned}
& d_{j}=\iota\left(h_{j}^{*}>0\right), j=m, f \\
& h_{m}^{*}=\phi_{m}^{\prime} W+\zeta_{m}^{\prime} z+\nu_{m} 0 \\
& h_{f}^{*}=\phi_{f}^{\prime} W+\zeta_{f}^{\prime} z+\nu_{f}+\left(1-d_{m}\right) S\left(\phi_{m}^{\prime} W+\zeta_{m}^{\prime} z+\nu_{m}\right)>0
\end{aligned}
$$

whereas, given (29), working hours are defined by (27).

The restriction to a switching regression model has some advantages and disadvantages. A clear advantage is that it is simpler: we do not have to take care of the coherency problem. The reason for this is that for the other partner we only model the participation decision. The model equation for the participation decision is not affected by the labour market state of the spouse. Once we introduce working hours for both spouses we also need to model the labour supply function off the participation frontier for both spouses. A related advantage is that the switching regression model can be used easier to test model restrictions, in particular the restrictions implied by (15) and (21): it is clear that a simple parameter restriction like $|s S|<1$ is not sufficient to ensure the coherency of a completely unrestricted system. There are also disavantages. Should we model the participation and hours of the wife, and restrict the analysis of the husband to information on participation only, or the other way around? In principle we could estimate the two different switching regression models and obtain two, potentially different, sets of parameter estimates for the same model. Donni (2003) concentrates his exposition on male working hours and participation and female participation. Blundell et al. (2001) 
suggest that for males only participation matters because in the UK most males either work 40 hours a week or do not work at all. They argue that variation in hours of males does not add much to the explanation in the first place. Thus, they model working hours and participation of the wifes and restrict themselves to the participation of the husbands. In our data for the Netherlands, roughly $70 \%$ of the working males works full-time hours (say 38-42). That implies that still a sizeable minority of the males work more or less than the standard working week. We recognize that especially the hours levels of the husbands that work nonstandard working weeks may provide interesting information for studying the relation between working hours of husband and wife. The effect of wage rates on male labour supply may be better identified if information on male working hours is used as well.

As a final remark we like to address the conceptual difference between Blundell et al. (2001) and Donni (2003) in the participation equation that describes the 'switch' of the regression. The reservation wage by Donni (2003) is the marginal rate of substitution between leisure and consumption at zero working, whereas the reservation wage rate by Blundell et al. (2001) is implicitly defined as the wage at which the utility level at zero hours equals the wage at fourty hours a week.

Blundell et al. (2001) require the ability to solve the reservation wage of husbands. This requires uniqueness and solvability of the reservation wage which may limit the choice of functional forms. The approach by Donni (2003) only requires optimal labour supply to be positive and the reservation wage does not need to be solved explicitly. If all regularity conditions and condition (5) is satisfied the participation rule based on labour supply or on the reservation wage are equivalent. But the model by Donni (2003) does not require to impose (5) to be able to estimate the model.

\subsection{On the identification}

Blundell et al. (2001) derive that under certain conditions the male participation index is identified up to a scale parameter and the indices for wages and female labour supply are identified up to unknown additive constant and the (equivalent of) parameter $S$ is identified. Recall that the model by Blundell et al. (2001) is comparable to the switching 
regression model (29) and (27). Therefore we first show how their conditions apply to (29) and (27). ${ }^{11}$

There are two order conditions for identification: "(i) other income, y, is a continuously distributed variable and is excluded from $x_{m}$ and $x_{f}$, the observed characteristics entering male and female wages" and "(ii) There is a continuously distributed variable among $x_{m}$ which is excluded from $w_{f}$ " (Blundell et al. (2001)). Order condition (i) is commonly made in all applied work on labour supply, either implicitly or explicitly. The condition can be used directly for the identification of the male participation index (up to scale), which is $\phi_{m}^{\prime} W+\zeta_{m}^{\prime} z$ in our case. ${ }^{12}$ Order condition (ii) consists of an exclusion restriction (which will be no problem in practical applications), and a continuity requirement (which may be harder to satisfy in practical situations. Order condition (ii) is used for the separate identification of the female hours index from the male participation index.

The rank conditions are more specific to the specification chosen. The equivalent of rank condition (iii) becomes: (iii) $\left(a_{6}, a_{7}\right) \neq(0,0) .{ }^{13}$ This condition is a direct implementation of order condition (i). Rank condition (iv) becomes (iv). $S \neq 0$ and $b_{2} \hat{w}_{m}+b_{4} \frac{\widehat{w_{m}}}{w_{m}+w_{f}}+b_{5} \widehat{w_{f}^{2}}$ and $b_{6} y+b_{7} \frac{\widehat{w_{m}}}{w_{m}+w_{f}} y$ are not colinear, with $\hat{w}_{j}=E w_{j}$, etc. Since $y$ is a continuous variable and $w_{m}$ contains a continuous variable the second part of the condition says that the effects of $w_{m}$ and $y$ should not cancel out. Note that by (23) $S \neq 0$ is satisfied if $R \neq 0, a_{4} \neq 0$ and $\Delta \neq 0$. The latter is satisfied if $\left(a_{4}, a_{6}\right) \neq(0,0)$ and $\left(b_{4}, b_{6}\right) \neq(0,0) .{ }^{14}$ Rank condition $(\mathrm{v}):(v) \phi_{m}^{\prime} W+\zeta_{m}^{\prime} z$ and $\phi_{f}^{\prime} W+\zeta_{f}^{\prime} z$ are not colinear. This condition speaks for itself.

The extended model (26) and (27) adds information on male working hours, which

\footnotetext{
11 There are, of course, differences in functional form between their model and the model in (29) and (27). In particular, own wage rates enter the hours and participation equations in (29) and (27) both linearly and quadratically, while the wage equations in (25) are log-linear, whereas the specification by Blundell et al. (2001) is completely linear in wages. As a consequence our model in (29) and (27) is less sensitive to colinearity. We would like to emphasize that this was not the motivation for our specification: we chose a labour supply function with a reasonable degree of flexibility, that allows for backward bending, is based on a preference specification with its roots in the literature, while we maintain the log-linear specification of wages.

12 The specification of the mirror model of (29) and (27) (a switching regression model for male working hours and participation given female participation), requires an equivalent mirror condition.

13 In the mirror model: $\left(b_{6}, b_{7}\right) \neq(0,0)$.

${ }^{14} R \neq 0$ is comparable to $\phi=1$ in Blundell et al. (2001).
} 
enables the identification of additional scale parameters, but also introduces the requirement to identify male working hours and participation outside the participation frontier. As an additional rank condition, we need (vi) $S \neq 1 / s$. Note that this condition is satisfied if the coherency constraint is satisfied: (vi)' $|s S|<1$.

\section{The Data}

We use data from the Socio-Economic Panel (SEP). The SEP is a household survey collected by Statistics Netherlands. We use data for the years 1990 to 1997. In this period, households were interviewed on a yearly basis, every May. An obvious advantage of this household survey is that not only the head of the household is interviewed, but also detailed information about the partner is obtained. We made several selections to arrive at the dataset that we will use in our analysis. For each year, we selected couples living together (either married or unmarried) without children, in which the male is in the age range of 22 to 60 and the female is no older than 60. We excluded households in which either husband or wife reports to be self-employed. Furthermore, we require the availability of information on the labour market state of both household members, the non-labour income, and information on the level of schooling and the sector of education. We use information on hourly wage rates and working hours of both partners, but we will also use information on individuals with missing working hours and wage rates. ${ }^{15}$ The pooled dataset contains 5486 observations (in which the observation unit is the two-member household).

Table 1 contains descriptive statistics for the pooled data. Note that $83.4 \%$ of the male respondents is employed and $69.2 \%$ of their female partners. In interpreting these numbers we should recall that we selected couples without children. Therefore, the percentages of males and females working are relatively high in our sample. At the household level we see that for $62.9 \%$ of the households both spouses are working and for $20.5 \%$ the husband works, while the wife does not. For $10.3 \%$ of the households none of the members is working, whereas for only $6.3 \%$ only the wife works.

\footnotetext{
${ }^{15}$ In the estimation, likelihood contributions will be adjusted accordingly.
} 
Note that on average the males in the sample are higher educated than the females. We have also information about the direction, or sector, of education and here we see some typical differences between males and females. There are few women with a technical type of education whereas the majority of the men followed a technical education. The majority of women is educated for the service sector. There are also more women without specialization in education. The mean age for males is about 2 years higher than for females, which is quite common for married couples.

Mean weekly working hours for males are about 39, whereas they are 31 for females. The male hourly wage rate is almost 4 guilders higher than the wage rate of females. The non-labour income includes interest income, income out of real estate, rent subsidy, income out of life insurance ("lijfrente"), gifts by family, income out of profits and scholarships. In the survey it is measured on a yearly basis and in table 1 it is converted to guilders per week. The average is about 34 guilders a week, and there is quite some variation in it, with some households reporting much higher amounts, and some households reporting not to have received any non-labour income.

Up till now we have looked at the pooled data which contained 5486 observations. Due to the panel character, there will be households with multiple observations as they may appear in different waves of the panel. Table 4 contains information about the number of times that the same households appear in the dataset. In fact, the 5486 observations of the pooled dataset are on 1637 different households. About $75 \%$ of the households appear more than once. Panel data techniques like random effects may be used to account for unobserved individual specific effects. For various reasons only a limited number of the households appears in all of the eight years. These include attrition (households either leave the panel or do not satisfy our selection criteria, like age, anymore), item nonresponse (relevant information is missing), wave nonresponse, or households may be new entrants in the panel. Throughout we maintain the assumption that nonresponse is independent of hours, wage rates, and employment status (as it is defined in this analysis). Note that attrition of households may also occur if a couple splits up: a household is considered the same through different waves if both of the partners remain the same two persons. 


\section{Estimation results}

We have estimated the model defined in (25)-(28) by the method of simulated maximum likelihood (SML). We use 60 replications to simulate wages (only for individuals without an observed wage). We found that the cross-effect between non-labour income and the male wage rate as a fraction of the wage rates of both spouses is neither significant in the labour supply equation of the males nor in that of the females. ${ }^{16}$ Therefore we present results without this cross effect.

\subsection{Parameter estimates of the 'reduced form' labour supply function}

In table 3 we present the estimates of the parameters of the labour supply function of husband and wife. The parameter estimates of the coefficients of the wage rates and non-labour income look very plausible. The level of the husband's own wage has a positive effect on his supply of labour, whereas the squared effect is negative, but relatively small in magnitude. The husband's wage rate expressed as a fraction has a positive effect, indicating that the husband supplies more labour the larger is his wage rate relative to his wife's wage rate. To evaluate the full effect of a change in the husband's wage rate we note that the marginal effect of $w_{m}$ on the supply of labour is $a_{2}+a_{4} w_{f} /\left(w_{m}+w_{f}\right)^{2}+2 a_{5} w_{m}$ which is definitely positive for all wage rates in the sample range. ${ }^{17}$ The effect on male labour supply of the level of the wife's wage rate is positive, but not significant. Non-labour income has a significant negative effect on the husband's supply of labour.

For the wife's labour supply we find similar effects of wages and non-labour income. The linear effect of the wife's own wage is positive. The wage fraction has a negative effect on the supply of labour by the wife, indicating that her supply of labour de-

\footnotetext{
16 The maximum likelihood test statistic takes the value 0.06. A consequence of this is that the collective cross-equation constraint between the labour supply equations of husband and wife $\left(b_{7} a_{4}=\right.$ $\left.a_{7} b_{4}\right)$ vanishes as it always holds if $a_{7}=b_{7}=0$.

17 To analyse the sensitiviy of the results to the inclusion of the share of the husband's wage rate, $w_{m} /\left(w_{m}+w_{f}\right)$, as a measure for the relative wages of husband and wife, we have also estimated the model with the $\log$ wage rate ratio, $\ln \left(w_{m} / w_{f}\right)$, as an alternative measure. This did not influence the outcomes. We will comment on this alternative in more detail later on.
} 
creases the larger is the wage rate of her husband relative to her own wage rate. The complete marginal effect of a change in the female wage rate on her labour supply is $b_{3}-b_{4} w_{m} /\left(w_{m}+w_{f}\right)^{2}+2 b_{5} w_{f}$ which is dominantly positive. Non-labour income has a negative effect on the wife's labour supply.

Note that the estimates of $a_{4}$ and $b_{4}$, the coefficients of the wage rate fraction, have the opposite sign, as required by the underlying collective model.

The covariates that have been included to represent observed heterogeneity are age and age squared of both partners, the level of education (with the highest level of education as reference level) and marital status. The husband's (wife's) labour supply rises with the husband's age until the age of 30 (36) after which it falls, whereas the husband's (wife's) labour supply falls (rises) with the wife's age until the age of 30 (23) after which it rises (falls). Wives with the lowest level of education have the lowest supply of labour. There is an interesting cross-partner effect of education: women with a lower educated husband have a lower supply of labour. Finally, recall that our sample consists of childless couples living together, so their marital status can be either married or or unmarried (even though we tend to present the results in terms of 'husband' and 'wife'). Marital status influences the male labour supply positively, but married women supply less labour than women who are living together without being married.

The parameter estimates of $s$ and $S$, that determine the husband's (wife's) labour supply if the wife (husband) does not work are positive and negative, respectively. In the estimated values, $|s S|=0.84$, so the coherency constraint $|s S|<1$ is not binding. The parameter $s$ is significant and, moreover, its impact is much larger than $S$, which is not estimated significantly. We comment on these differences when we discuss the results of the sharing rule.

\subsection{Estimates of individual labour supply and the sharing rule}

Using the estimates of the parameters of the reduced form labour supply equations from table 3, we can compute the parameters of the individual labour supply functions (10) and the sharing rule (11) using the expressions in (13) and below. Thus we can decompose the total effect on labour supply into effects due to individual preferences and 
into the effects due to the sharing rule. Table 4 contains the parameters of the individual labour supply functions (10). The standard errors have been computed using the delta method. The estimates of the parameters of non-labour income ${ }^{18}$ show a significant and negative effect in the individual labour supply functions of both spouses. Thus, leisure is a normal good according to the underlying preference structure. For the husbands we find a significant effect of the own wage on labour supply, whereas the quadratic effect is negative, but so small that backward bending does not occur for wage rates within in the sample range. For the wifes we find a similar result.

Table 5 contains the estimates of the sharing rule (11). ${ }^{19}$ Before we discussed the problem of obtaining precise estimates of the sharing rule. Table 5 shows that all of the coefficients of the sharing rule are estimated significantly. Important for this significant result is that we found precise estimates of $a_{4}, b_{4}, a_{6}$ and $b_{6}$ and that $a_{4}$ and $b_{4}$ have the opposite sign. The importance of this follows from our discussion in section 3 around the specification of the sharing rule and from the discussion on identification. Note that table 5 contains the coefficients of the 'share' of the husband $\rho_{m}$. The coefficients of the wife's 'share' follow trivially from this as $\rho_{f}=y-\rho_{m}$ which implies that signs the coefficients of the wage rates and the wage fraction reverse, whereas the coefficient of non-labour income in the wife's share is $1-0.61=0.39$.

The coefficients of the levels of the husband's wage rate and the wife's wage rate are positive and negative respectively, whereas the impact of the husband's wage rate is somewhat larger. This implies that if both the husband's and the wife's were the same and if they would rise with the same percentage (such that the wage rate fraction remains unchanged), ${ }^{20}$ the 'share' of the husband would rise. In practice, the levels of wage rates of husband and wife differ, but since, on average, male wage rates are larger than female wage rates a rise in wage rates of males and females would in most cases lead to an increase in the 'share' of the male, and, consequently, a decrease in the 'share' of the female. The parameters in table 4 show the effect of such an increase in wage

\footnotetext{
${ }^{18}$ Recall that the parameter of non-labour income determines the effect of the individual's 'share' on the individual's labour supply.

19 Standard errors have again been computed using the delta method.

${ }^{20}$ This type of wage change for both spouses may happen if both spouses experience a periodic wage increase.
} 
rates on the supply of labour of males and females: there is a direct effect of wages on the individual labour supply function, and there is an indirect effect running through the sharing rule. The direct effect is positive for both spouses, but since the husband's share increases, and leisure is a normal good, there is an opposing negative effect of the increasing 'share' for husband, whereas the decreasing wife's share influences her supply of labour positively. The reduced form parameters in table 3 show the total effect and show that in the end both the working hours of the husband and working hours of the wife will increase by this type of percentual wage rate change. For couples for which the wife's wage rate is sufficiently larger than the husband's, the share of the husband will decrease instead.

Now we consider what happens if the wage rate of the husband increases, while the wage rate of the wife remains the same. Now also the wage fraction will change. The marginal effect of a change in $w_{m}$ on the sharing rule is $k_{2}+k_{4} w_{f} /\left(w_{m}+w_{f}\right)^{2}$. The effect of the level, $k_{2}$, is positive and increases the male's 'share'. The effect of the wage fraction, $k_{4}$, is negative, but the impact of the wage fraction will become smaller the larger is the husband's wage rate relative to the wife's wage rate. Which effect dominates depends on the level of the wage rates. To get a feeling for this, we computed for all couples with observed wage rates in the sample the marginal effect $k_{2}+k_{4} w_{f} /\left(w_{m}+w_{f}\right)^{2}$ and we considered the percentage of households for which the effect is positive. The effect is positive for only $7.3 \%$ of these sample observations. Thus, an increase in the husband wage rate increases the 'share' of the wife for most observations. The consequence of the increase in the wife's share is that her supply of labour will diminish since leisure is a normal good to her. The husband's share decreases and in addition, there is the direct effect of the increase in his wage rate on his labour supply, so in total the husband will increase his supply of labour.

In a similar way, we may evaluate the effect of an increase in the wife's wage rate if the husband's wage rate remains the same. The marginal effect of the wife's wage rate on the sharing rule is $k_{3}-k_{4} w_{m} /\left(w_{m}+w_{f}\right)^{2}$. This is positive for $99 \%$ of the couples with observed wage rates in the sample. Thus, an increase in the wife's wage rate apparently leads to an increase in the husband's share. The labour supply of the husband will be 
reduced whereas the wife's supply of labour will increase.

The analysis above shows that the marginal effect of the wage rates of husband and wife on the sharing rule depend on the particular relative wage measure chosen. To see if the results are affected if we choose an alternative measure for the relative wages, we also estimated the model with the $\log$ of the wage rate ratio, $\ln \left(w_{m} / w_{f}\right)$ as an alternative measure for the relative wages. The estimates show that both the qualitive and quantitative implications are not affected. For instance, the marginal effect of an increase in the wage rate of the husband on the husband's 'share', keeping the wage rate of the wife constant, now is given by $k_{2}+k_{4} / w_{m}=20.8-656 / w_{m}$ which is negatve for $95 \%$ of the sample, whereas the marginal effect of an increase in the wife's wage rate on the husband's 'share' is given by $k_{3}-k_{4} / w_{f}=-17.4+656 / w_{f}$ which is positive for $99 \%$ of the observations.

If non-labour income increases, 0.61 of it is used to increase the husband's 'share', whereas the remaining 0.39 is assigned to the wife. As a consequence, both will decrease their supply of labour. The part that is assigned to the husband is larger, but given the standard error of the estimate, we cannot reject that the couple decides to equally split the additional non-labour income.

Evaluating the outcomes of the sharing rule, we can say that the effect of an increase in the wage rates of husband and wife which keeps the wage ratio constant are well interpretable in terms of bargaining power: the 'share' changes in favour of the spouse with the largest absolute increase in the wage, although it should be noted that the husband is in a more favourable position since the impact of the husband's wage rate on the sharing rule is somewhat larger. A unilateral increase in the wage rate of one of the spouses shows that the spouse whose wage has increased transfers money to his/her partner, as the partner's 'share' is increased. In general, we expect that a change in the relative wage rate of husband and wife affects the 'share' both because the relative importance of the wage incomes of husband and wife in total household income changes, and because the relative bargaining power of husband and wife is affected. The outcomes of the model imply that the relative supply of labour within the household is shifted towards the partner with the wage increase. Caring preferences may be an easy explanation for 
transferring money to the other parner, but a more appealing explanation is that the decrease in labour supply by the other partner goes together with an increase in household production, instead of a sheer increase in leisure. Then the substitution in working hours between the partners may come together with a substitution in time spent on housekeeping activities.

We may also compute the sharing rule for the case in which the husband (wife) works and the wife (husband) not (see (17) and (22)). The results are in table 6. Notably the sharing rule for a working husband and a nonworking wife is different from the rule in table 5, which is due to the large value of the estimate of $r$ in (17). The estimate of $R$ in (22) is much smaller and is not significantly different from zero. Reservation wages of nonworking males may be much lower and show less variation than reservation wages of nonworking females. This may explain why the sharing rule for working males with nonworking wifes differs much more from the sharing rule in table 5 . Note that, though the coefficients are significant at the 5 or $10 \%$ level, the standard errors show that the point estimates are not very precise. This becomes more clear once we consider the coefficient estimate of nonlabour income, which has a value of 26.0, which is outside the range of reasonable values, which is (close to) the range of zero to one. The increase in the estimate of the effect of non-labour income, compared to the sharing rule in table 5 , suggests quite an increase in the bargaining power of the husband, now that the wife is nonworking. Also, note that the coefficient of the fraction of the wage rate of the husband now is positive: an increase in the wage rate of the husband now leads to an increase in the 'share' of the husband. This is an appealing result in view of the earlier discussion, since the subsitution between male and female working hours is absent now: a change in the wife's wage rate does not affect total household income and the wife cannot decrease working hours if the wage rate of the husband rises. Thus it makes no sense to transfer additional income to the wife as her maximum time available for housekeeping activities cannot be increased any further. From this we may conclude that the direction in which the coefficients of the sharing rule change, if the wife is not working instead of working, is quite plausible and consistent with a bargaining power interpretation, but the estimates of the coefficients are, although signficantly different 
from zero, imprecise.

\subsection{Estimates of the wage equations and the co-variance struc- ture}

Table 7 contains the estimates of the parameters of the wage equations (25) of husband and wife. The age effects imply rising wages for males whereas female wages top at the age of 43. Both male and female wage increase with the level of education (highest level of education is the reference level). Males and females with an economic/administrative type of education have, on average, higher wages (with the service sector as the reference sector). We see some indications that wages rise over time ((1990) is the reference year).

Finally, table 8 shows the estimates of the covariance matrix in (28). The covariance between the unobserved components in male and female labour supply is positive and signficant and implies a correlation coefficient of 0.28. Furthermore, the correlation between errors in male and female wages is positive and significant, but the size of the correlation coefficient is only 0.047 .

\subsection{Restrictions on the Slutsky matrix}

The unitary model implies symmetry of the Slutsky matrix. In section 3.2 we noted that symmetry imposes 9 parameter restrictions on the labour supply model in (12), which become 7 , since we have already found that setting $a_{7}=b_{7}=0$ is not rejected by the data. We have estimated the model with the symmetry constraints imposed and found that the likelihood ratio test for testing the null hypothesis that the 7 restrictions are satisfied is 3756 , which implies a rejection of the symmetry of the Slutsky matrix implied by the unitary model. Another restriction of the unitary model is that the own compensated wage effect is positive (or: $S_{j j}>0$ ). Given the outcomes of the coefficient estimates in table 3 , this condition is met for both male and female labour supply for the wage rates within the sample range.

The own compensated wage effect of the individual labour supply function is positive (i.e. $\left.\alpha_{3}^{j}+2 \alpha_{4}^{j} w_{j}-h_{j} \alpha_{2}^{j}, j=m, f\right)$ for both males and females for the given sample range of wage rates. 
We ran an extended variant of the model in which we also included the female (male) wage rate squared in the reduced form labour supply function of the husband (wife). Thus we allow for more flexibility of the underlying sharing rule. The likelihood ratio test statistic (two degrees of freedom) is 5.3, which implies that exclusion of the squared wage rates is not rejected at the $5 \%$ level. $^{21}$

\subsection{A random effects specification}

We may exploit the panel feature of our data to allow for random effects in the model. For the identification of a random effects model we need a sufficient number of households that is observed for two or more periods. Table 2 shows that we have observations on 1637 observations and that 1435 of these households are observed for two or more years.

A point of concern is the variation in working hours within households. If someone keeps the same job and working conditions for some years there may be little variation across time in labour market state and working hours of a given household member. A consequence may be that an individual specific time invariant random effect may take away much of the explanatory power of the structural explanatory variables like the wage rates and the non-labour income, which can lead to imprecise estimates. To get a feeling for the variation in working hours within households, we computed the average across households of the variance of the working hours of each household member for household members with positive working hours. ${ }^{22}$ This results in a standard deviation of 3.4 for working hours of husbands and 3.5 for working hours of wives. These numbers may be compared to the standard deviations of working hours of the pooled data set found in table 1 , which are 7.4 and 10.8 respectively, which are obviously larger numbers. We also tried to gain insight in the changes in labour market states across time for members of a given household. ${ }^{23}$ Of the husbands, $73.3 \%$ (of the 1637 observations) is observed to be

\footnotetext{
${ }^{21}$ We also found that the quantitative impact of the squares wage rates in the sharing rule was quite small, and that the point estimates of the sharing rule became insignificant, suggesting an overflexibility of the specification.

${ }^{22}$ In computing this measure we also included households with one period of observation, which somewhat lowers the variance (by a fraction 1435/1637).

23 The more different waves are observed for a given household, the larger the chance that we observe a change, given everything else. In the measure we present, though, we do not distinguish by the number of available waves, since this is not relevant for gaining insight in the variation in labour market states
} 
working in all waves, whereas $13.2 \%$ is observed to be not working in all of the available waves. For the resulting $13.5 \%$ of the husbands we observe a change in the labour market state. For the women, these numbers are 59.4\%, 26.5\% and $14.1 \%$ respectively. Since we have a relatively large dataset, there seems to be sufficient variation in working hours and labour market state to estimate a random effects variant of our collective household labour supply model, but it is clear that the risk of obtaining imprecise estimates is present as well.

We extend the model equations in (25) and (26) by introducing a household specific random effect into the model. We add the subscripts $i$ and $t$ as indicators for household $i$ and time period $t$. The model equations now read

$$
\begin{aligned}
& \ln w_{i t j}=\eta_{j}^{\prime} x_{i t j}+\omega_{i j}+u_{i t j} \\
& d_{i t j}=\iota\left(h_{i t j}^{*}>0\right), j=m, f \\
& h_{i t f}^{*}=\phi_{f}^{\prime} W_{i t}+\zeta_{f}^{\prime} z_{i t}+\theta_{i f}+\nu_{i t f}+\left(1-d_{i t m}\right) S\left(\phi_{m}^{\prime} W_{i t}+\zeta_{m}^{\prime} z_{i t}+\theta_{i m}+\nu_{i t m}\right) \\
& h_{i t m}^{*}=\phi_{m}^{\prime} W_{i t}+\zeta_{m}^{\prime} z_{i t}+\theta_{i m}+\nu_{i t m}+\left(1-d_{i t f}\right) s\left(\phi_{f}^{\prime} W_{i t}+\zeta_{f}^{\prime} z_{i t}+\theta_{i f}+\nu_{i t f}\right), \\
& i=1, \ldots, N, t=1, \ldots, T_{i}
\end{aligned}
$$

In (30), $\omega_{i j}$ and $\theta_{i j}$ represent the random effects of partner $j, j=m, f$ in household $i$ in the wage equation and the labour supply equation, respectively. The panel is unbalanced, so the number of time periods per household, $T_{i}$, varies with $i$. For the time varying error terms $\left(\nu_{i t m}, \nu_{i t f}, u_{i t m}, u_{i t f}\right)^{\prime}$ we assume that they are independently and identically distributed across households and across time and we make the assumption (28), as before. Moveover, we assume them to be uncorrelated with the random effects $\left(\theta_{i m}, \theta_{i f}, \omega_{i m}, \omega_{i f}\right)^{\prime}$, and uncorrelated with the observed characteristics. We assume that the random effects are normally distributed:

$$
\left(\begin{array}{c}
\theta_{i m} \\
\theta_{i f} \\
\omega_{i m} \\
\omega_{i f}
\end{array}\right) \sim N\left(\left(\begin{array}{c}
0 \\
0 \\
0 \\
0
\end{array}\right),\left(\begin{array}{cccc}
\sigma_{\theta, m}^{2} & \sigma_{\theta, m f} & \sigma_{\theta \omega, m} & \sigma_{\theta \omega, m f} \\
\sigma_{\theta, m f} & \sigma_{\theta, f}^{2} & \sigma_{\theta \omega, f m} & \sigma_{\theta \omega, f} \\
\sigma_{\theta \omega, m u} & \sigma_{\theta \omega, f m} & \sigma_{\omega, m}^{2} & \sigma_{\omega, m f} \\
\sigma_{\theta \omega, m f} & \sigma_{\theta \omega, f} & \sigma_{\omega, m f} & \sigma_{\omega, f}^{2}
\end{array}\right)\right)
$$

that is available for the estimation of the random effects model. Note that the frequency presented also includes households that are observed for one period only. 
The random effects are indepedently distributed across households and uncorrelated with the observed characteristics. For the identification of the covariance structure we excluded the time dummy for the year 1991 from the wage equations. For the remaining, the model specification and the variables included remain the same.

To estimate the model, we extended the simulated maximum likelihood procedure: we integrate over the random effects using $R=60$ drawings from (31) for each household.

The parameter estimates of the random effects model are shown in tables 9 through 14. We will discuss the main differences with the previous results in tables 3 through 8 .

The labour supply functions for husbands in tables 9 and 10 show that the labour supply of the husband is much less sensitive with respect to the husband's wage rate than we found before. This suggests that before the husband's wage rate picked up a great deal of heterogeneity. The negative impact of the husband's wage rate squared, which represents the backward bending of the labour supply function, is now so large that the esimates imply that an increase in the husband's wage rate leads to a decrease in working hours, both according to the 'reduced form' labour supply function and according to the 'structural' labour supply function. ${ }^{24}$ The parameter estimates of the random effects model imply that leisure is a normal good to the husband, as was also concluded from the estimation with the pooled data.

The parameters of the labour supply function of the wife are remarkably robust to the inclusion of random effects, which becomes clear once we compare the female individual labour supply parameters in tables 4 and 10. The estimates imply that leisure is a normal good to the woman and that an increase in her wage rate leads to an increase in her supply of labour.

If we compare the sharing rule parameters in table 11 with the estimates in table 5 , we see that the wife's wage rate has a relatively higher negative impact on the 'share', which suggests more bargaining power for the wife. An increase in the husband's wage rate leads, as was found before, to a decrease in the husband's 'share' for most observations

\footnotetext{
${ }^{24}$ We have also estimated the model without the husband's wage rate squared. This also showed a negative impact of the wage rate on male labour supply. We have also estimated several model variants in which we restricted some or all of the off-diagonal elements of the covariance matrix in (31) to zero, but in any case we found that the male wage rate influences male labour supply negatively. Thus, this negative effect is really caused by the inclusion of the random effects itself.
} 
in the sample range. This again confirms the story that the husband transfers part of his increase in wage income to the wife, such that she reduces her working hours.

In contrast to the previous result, an increase in the wife's wage rate now decreases the husband's 'share' for the majority of the observations. The net effect for the wife's labour supply is positive, as before, but now the decrease in the husband's 'share' leads to an increase in the husband's working hours as well, since leisure is a normal good to him.

Taken together, an increase in the wage rate of the husband is partly used to decrease the working hours of the wife, but reversely, an increase in the wage rate of the wife is not used to decrease the working hours of the husband.

The impact of nonlabour income on the 'share' now is different as well. The estimate suggests that an increase in nonlabour income of the household is almost completely assigned to the husband and, consequently, used to decrease the husband's working hours, while the wife's 'share' and working hours remain unaffected. This explains the small and insignificant effect of nonlabour income in the wife's reduced form labour supply function in table 9.

Table 12 shows that the sharing rule for households in which the wife works while the husband does not is again very similar to the sharing rule for working partners. The sharing rule for households in which the husband works while the wife does not is again very different, and the point estimates of the parameters are imprecise. However, the value of the parameter of nonlabour income now looks much more reasonable than before. As before, an increase in the wage rate of the husband leads to an increase in the husband's 'share'. This again suggests a higher power for working men with a nonworking wife, compared to working men with a working wife.

The random effects estimates of the wage equations in table 13 show no large differences with the estimates in table 7 .

The estimates of the covariance structure of the random effects in table 14 show that all of the off-diagonal correlation coefficients are estimated significantly.

Summarizing we may say that the effect of the male wage rate in the male labour supply function is affected most by the inclusion of random effects. The female labour 
supply function is not affected. For the sharing rule some results are robust to the inclusion of random effects while others are not. Robust is the result that an increase in the husband's wage rate is partly transferred to the wife such that she can reduce her working hours. Also robust is the result that a husband with a non-working wife gets a higher 'share' if his wage rate increases or if non-labour income increases. The effect of the wife's wage rate on the husband's 'share' was positive in the pooled estimation, implying a decrease in the husband's supply of labour, but is negative according to the random effects model. The estimates obtained with the pooled model imply that an increase in the household's non-labour income is split up between household members such that the working hours of both members are reduced, while the random effects model suggests that the increase in non-labour income is completely assigned to the husband, such that his working hours are reduced, while the wife' working hours remain unaffected.

\section{Conclusions}

Until recently, empirical applications of the collective household labour supply model were based on datasets in which both spouses are employed. Recent work by Blundell et al. (2001) and Donni (2003) addressed the issue of nonparticipation in collective household labour supply models. They address the problem of nonuniqueness of the reservation wage in the collective model, and introduce additional assumptions about the behaviour of households in which one spouse is nonparticipating. An important assumption is that the bargaining power of the nonparticipating household member still can be represented by his or her wage rate. However, the impact of a change in the wage rate of the nonparticipating member on the sharing rule will be different from the situation in which both spouses are working, as the wage rate will affect the relative bargaining power of household members, but it will not affect the actual total household income. Donni (2003) and Blundell et al. (2001) both come with suggestions for an empirical specification, and Blundell et al. (2001) actually apply their approach to a sample of UK data, and thoroughly discuss the identification of the model parameters. 
The importance of the inclusion of nonparticipating partners in the estimation of the collective labour supply model is obvious, since their neglectance may lead to selectivity bias in the estimates of the sharing rule and the labour supply functions of the household members.

Following the initial framework by Donni (2003), we specify an empirical model of collective household labour supply that allows for nonparticipation of husband and wife. In our model we use information on both the participation and the working hours of husband and wife. To make this possible, we have to pay particular attention to the coherency of the model. For our specification we derive a restriction on the parameter space such that coherency of the model is satisfied.

As a basis for our model we specify the labour supply function, based on individual preferences, as a function that is quadratic in wage rates and linear in non-labour income. The specification of the sharing rule deserves particular attention, as empirical work on collective household labour supply shows that coefficients of the sharing rule are often imprecisely estimated. We specify a sharing rule that, apart from the wage rates of both spouses, contains a measure for the relative wage rates of both spouses to represent the relative bargaining power as well as the relative marginal impact of working hours on total household income. Moreover, the sharing rule contains non-labour income as well as a cross-effect of non-labour income and the relative wage measure. As a measure for the relative wage rates we took the wage rate of the husband, expressed as a fraction of the sum of the wage rates of husband and wife. ${ }^{25}$ By filling out the sharing rule in the individual labour supply function, we obtain the 'reduced form' labour supply function that will used in the estimation of the model. This labour supply function for a given household member includes the wage rates of both household members, is quadratic in the own wage rate, includes the measure for the relative wage rates, nonlabour income and the cross-effect of non-labour income and tge relative wage rates. Thus, our specification is quite flexible with respect to wage rates, and allows for a backward bending labour supply function as well as for cross-effects of non-labour income.

\footnotetext{
${ }^{25}$ As a sensitivity analysis, we have also estimated the model with an alternative measure, the log of the wage rate ratio. Both the qualitative and the quantitative results proved to be insensitive to this change.
} 
The parameters of the 'reduced form' labour supply model will be estimated, but the underlying parameters of the sharing rule and preferences can be recovered from them.

We use data from the Dutch Socio Economic Panel (SEP) over the period 1990-1997. As this household survey contains detailed information on both partners, it is very suitable to analyse the joint household labour supply behaviour. We select a (pooled) sample of 5486 observations on couples without children. If we consider the panel character, we have an unbalanced panel on 1637 different households in which the number of waves per household varies from one to eight. The data contains information on the labour market state, working hours, wage rates and non-labour income, as well as information on individual and household characteristics, like the age of the members, the level of education and their marital status. The panel character of the dataset allows us to include random effects in the labour supply and wage equations.

We estimate the parameters of the labour supply functions and the wage equations of husband and wife simultaneously, allowing for correlations in unobserved components. We estimated both a model specfication without random effects and a specification with random effects. We use the method of simulated maximum likelihood to integrate over the unobserved wages of the nonparticipants, and over the unobserved random effects. By analyzing the sensitivity of the results to the inclusion of random effects we gain insight in the importance of unobserved individual and household specific elements and the robustness of the results.

The parameter estimates of the 'reduced form' labour supply funcions can be used to recover the parameters of the sharing rule and the 'structural' labour supply function.

The outcomes of the 'reduced form' and 'structural' labour supply functions of the wife are rather insensitive to the inclusion of random effects. The 'structural' labour supply function shows that a rise in the wife's wage rate leads to an increase in working hours and that leisure is a normal good. Backward bending of the labour supply function is not very strong. The effect of the male wage rate expressed as a fraction of the sum of both wage rates is negative.

The parameter estimates of the labour supply of the husband are sensitive to the inclusion of random effects. The estimates without random effects show a positive effect 
of the male wage rate in both the 'reduced' form and the 'structural' labour supply functions. In the random effects specification, the sensitivity of labour supply with respect to the male wage rate is greatly reduced, and, moreover, the effect becomes negative. This implies that time invariant unobserved household characteristics pick up much of the explanation of the working hours that was explained by wage rates before. It is possible that the lack of variation across time in working hours and labour market state for males within a household complicates the identification of the impact of wage rates on labour supply once random effects are accounted for. Non-labour income has a significant negative effect on male labour supply and this effect is robust with respect to the inclusion of random effects. ${ }^{26}$ The effect of the male wage rate expressed as a fraction of the sum of both wage rates is positive, showing that there is a positive effect on male working hours if the male's wage rate rises relative to the female's wage rate.

We obtained significant coefficient estimates for the sharing rule, also for the random effects specification. Some results are robust to the inclusion of random effects while others are not. The estimates of the sharing rule provide us insight in the division of income and labour between the household members.

Without random effects, the coefficient estimate of non-labour income in the sharing rule suggests that if the household's non-labour income increases, both the 'share' of the husband and the 'share' of the wife increase, implying that both partners will reduce their supply of labour. The point estimate suggests that the 'share' of the husband increases somewhat more, but given the standard error it cannot be rejected that the spouses simply split the additional income in two equal halves. Once we allow for random effects, we cannot reject that an increase in non-labour income is completely assigned to the husband, such that the husband's working hours are reduced, while the wife's labour supply remains unaffected.

An increase in the wage rate of the husband, while the wage rate of the wife remains unchanged, decreases the 'share' of the husband for the vaste majority of wage rates in the sample range. Thus, the wife's 'share' increases and the wife's working hours decrease. This result is robust to the inclusion of random effects. The result shows that

\footnotetext{
26 The cross-effect of non-labour income and the relative wage measure was not significant.
} 
the husband transfers part of the increase in wage income to his wife. This may be due to the existence of caring preferences. Alternatively, the decrease in working hours by the wife may enable her to increase her time spent on household production.

The effect of an increase in the wife's wage rate is not robust to the inclusion of random effect. Without random effects, the increase in the wife's wage rate increases the husband's 'share', and consequently reduces his supply of labour and increases the wife's working hours. Once random effects are included, an increase in the wife's wage rate still increases the wife's working hours, but the 'share' of the husband is decreased, so the the husband's working hours increase as well.

We can also derive the parameters for the sharing rule of households with a working husband and a nonworking wife, and households with a nonworking husband and a working wife. The sharing rule of a working wife and a nonworking husband is not significantly different from the sharing rule for both partners working. The reason for this may be that reservation wages of males tend to be very low and show little variation. The sharing rule for a working husband with a nonworking wife differs considerably from the sharing rule for working partners. The coefficient estimates are significant at the 5 or $10 \%$ level, but the confidence intervals are large. The results suggest that now the increase in the 'share' of the husband is higher relative to the increase in the 'share' of the wife if the household's non-labour income is increased. Moreover, a unilateral increase in the husband's wage rate now leads to an increase in the husband's 'share'. This suggests an increase in bargaining power of the husband if the wife is not working. Now that the wife is not working, her time available for household production cannot be increased any further by increasing her 'share'. Therefore, the relative wage rate as it appears in the sharing rule now is more likely to represent a pure bargaining power effect, instead of the relative importance of the partners' working hours in total household income. This result is robust to the inclusion of random effects.

Additional insight in the household labour supply behaviour is obtained from the included observed characteristics. We have to be careful in interpreting the effects of observed heterogeneity in the labour supply function, because the location of the labour supply function is non-parametrically not identified, as shown by Blundell et al. (2001), 
and we do not know whether the estimated effects of observed heterogeneity stem from their impact on preferences, or from their impact on bargaining power, or maybe both. A remarkable effect is that a wife with a lower educated husband supplies less labour. In our sample we have childless couples who can be either married or living together. Marital status influences the husband's supply of labour positively, but married women supply less labour than unmarried women. As noted before, this may be both due to the impact of marital status on bargaining power and on individual preferences.

We ran some additional tests and checks for the preferences underlying the estimated labour supply functions. We derived the parameter restrictions that the symmetry of the Slutsky matrix (a requirement of the unitary model) imposes on the 'reduced form' labour supply equations. Symmetry of the Slutsky matrix was rejected by the likelihood ratio test. We also checked whether positivity of the own compensated wage effect was satisfied by the 'reduced form' labour supply functions and by the underlying 'structural' individual labour supply functions. We find that for the estimates with the pooled data this condition is satisfied for all values of wage rates within the sample range for both spouses and for both the 'reduced form' and the 'structural' labour supply equations. In the random effects model, the condition is violated for the labour supply of the husband. 


\section{A On the coherency of the model}

In this appendix we show how we may derive restrictions on the parameters $s$ and $S$ in order to get coherency. To simplify notation, we denote the right hand side of (24) by $X_{j}^{\prime} \beta_{j}$ for the purpose of this exercise:

$$
X_{j}^{\prime} \beta_{j}=\phi_{j}^{\prime} W+\zeta_{j}^{\prime} z+\nu_{j}, j=m, f
$$

Thus, we may rewrite model (26) as

$$
\begin{aligned}
d_{m}^{*} & =X_{m}^{\prime} \beta_{m}+\left(1-d_{f}\right) s X_{f}^{\prime} \beta_{f} \\
d_{f}^{*} & =X_{f}^{\prime} \beta_{f}+\left(1-d_{m}\right) S X_{m}^{\prime} \beta_{m} \\
d_{j} & =\iota\left(d_{j}^{*}>0\right)
\end{aligned}
$$

First, let us explain what coherency implies in the context of this model. Consider the case in which both spouses choose to work: $d_{m}=1, d_{f}=1$. The model in (33) generates this outcome if both $X_{m}^{\prime} \beta_{m}>0$ and $X_{f}^{\prime} \beta_{f}>0$. The model would be incoherent if the model can generate a second outcome as well, for instance, $d_{m}=0, d_{f}=0$ by $X_{m}^{\prime} \beta_{m}+s X_{f}^{\prime} \beta_{f} \leq 0$ and $X_{f}^{\prime} \beta_{f}+S X_{m}^{\prime} \beta_{m} \leq 0$. Now let us concentrate on this possible source of coherency, since the other outcomes, $d_{m}=1, d_{f}=0$ and $d_{m}=0, d_{f}=1$ cannot be generated by the model simultaneously with $d_{m}=1, d_{f}=1$. Let us consider when the events

$$
\begin{aligned}
& X_{m}^{\prime} \beta_{m}>0 \\
& X_{f}^{\prime} \beta_{f}>0
\end{aligned}
$$

and

$$
\begin{aligned}
& X_{m}^{\prime} \beta_{m}+s X_{f}^{\prime} \beta_{f} \leq 0 \\
& X_{f}^{\prime} \beta_{f}+S X_{m}^{\prime} \beta_{m} \leq 0
\end{aligned}
$$

may occur simultaneously. Note that (34) and (35) cannot occur together if either $s \geq 0$ or $S \geq 0 .{ }^{27}$ The two events could occur, though, if both $s<0$ and $S<0$. Combining (34) and (35) yields two conditions:

$$
s<-\frac{X_{m}^{\prime} \beta_{m}}{X_{f}^{\prime} \beta_{f}}(<0)
$$

and

$$
-\frac{X_{m}^{\prime} \beta_{m}}{X_{f}^{\prime} \beta_{f}}<\frac{1}{S}(<0)
$$

\footnotetext{
${ }^{27}$ For identification we need $s \neq 1 / S$, but that is a different story than coherency.
} 
Combining (36) and (37) yields $s<1 / S$. To prevent this from happening we need the reverse to hold, so $s>1 / S$. So if $s<0$ and $S<0$, a condition to ensure that the model does not generate the two outcomes $d_{m}=1, d_{f}=1$ and $d_{m}=0, d_{f}=0$ at the same time is $s S<1$.

Next, note that the model outcomes $d_{m}=1, d_{f}=0$ and $d_{m}=0, d_{f}=1$ are not exclusive a priori either. The model generates these two outcomes, respectively if

$$
\begin{aligned}
& X_{m}^{\prime} \beta_{m}+s X_{f}^{\prime} \beta_{f}>0 \\
& X_{f}^{\prime} \beta_{f} \leq 0
\end{aligned}
$$

and

$$
\begin{aligned}
& X_{m}^{\prime} \beta_{m} \leq 0 \\
& X_{f}^{\prime} \beta_{f}+S X_{m}^{\prime} \beta_{m}>0
\end{aligned}
$$

Again, note that (38) and (39) cannot occur simultaneousy if either $s>0$ or $S>0$. If $s<0$ and $S<0$, combining (38) and (39) again yields the conditions (36) and (37). So again, we have $s S<1$ if $s<0$ and $S<0$ to impose coherency.

Finally, reconsider (35). We may rewrite these conditions as

$$
\begin{aligned}
& S\left(X_{m}^{\prime} \beta_{m}+s^{*} X_{f}^{\prime} \beta_{f}\right) \leq 0 \\
& s\left(X_{f}^{\prime} \beta_{f}+S^{*} X_{m}^{\prime} \beta_{m}\right) \leq 0
\end{aligned}
$$

with $s^{*}=1 / S$ and $S^{*}=1 / s$. First, assume that $s>0$ and $S>0$. Then (40) implies

$$
\begin{aligned}
& X_{m}^{\prime} \beta_{m}+s^{*} X_{f}^{\prime} \beta_{f} \leq 0 \\
& X_{f}^{\prime} \beta_{f}+S^{*} X_{m}^{\prime} \beta_{m} \leq 0
\end{aligned}
$$

This case does not imply incoherency, but we do see that there is a identification problem since parameters $\left(s^{*}, S^{*}\right)$ will lead to the same probability as $(s, S)$. Imposing $s S<1$ for all positive values of $s$ and $S$ clearly excludes $\left(s^{*}, S^{*}\right)$.

Next, assume that $s<0$ and $S>0$. Then (40) implies

$$
\begin{aligned}
& X_{m}^{\prime} \beta_{m}+s^{*} X_{f}^{\prime} \beta_{f} \leq 0 \\
& X_{f}^{\prime} \beta_{f}+S^{*} X_{m}^{\prime} \beta_{m} \geq 0
\end{aligned}
$$

Thus, the outcome generated by the model is not unique. We have a combined coherenyidentification problem here, which can easily be excluded by assuming $|s S|<1$. The same holds for the case $s>0, S<0$. The final case $s<0, S<0$ has already been covered above. 
Summarizing, we have the following result: a sufficient condition for coherency of the model is $|s S|<1$.

Note that it is not necessary to restrict either $s$ or $S$ to zero, as in the model by Heckman (1978) for limited dependent variables with endogenous right hand side variables, which in our notation reads

$$
\begin{aligned}
d_{m}^{*} & =X_{m}^{\prime} \beta_{m}+\left(1-d_{f}\right) s \\
d_{f}^{*} & =X_{f}^{\prime} \beta_{f}+\left(1-d_{m}\right) S \\
d_{j} & =\iota\left(d_{j}^{*}>0\right)
\end{aligned}
$$

Using similar arguments as above, it is readily established that (43) requires $s S=0$ for coherency, as was shown by Heckman (1978). 
Table 1: descriptive statistics of the pooled data: 5486 observations

\begin{tabular}{|c|c|c|c|}
\hline Variable & Husband & & Wife \\
\hline \multicolumn{4}{|l|}{ Employment status } \\
\hline Employed & $83.4 \%$ & & $69.2 \%$ \\
\hline Not Employed & $16.6 \%$ & & $30.8 \%$ \\
\hline \multicolumn{4}{|l|}{ Education level } \\
\hline Primary & $8.7 \%$ & & $12.8 \%$ \\
\hline Lower vocational & $17.6 \%$ & & $24.6 \%$ \\
\hline Intermediate & $48.7 \%$ & & $41.9 \%$ \\
\hline Higher Vocational & $18.9 \%$ & & $17.4 \%$ \\
\hline University degree & $5.8 \%$ & & $3.4 \%$ \\
\hline \multicolumn{4}{|l|}{ Education sector } \\
\hline Technical & $35.7 \%$ & & $5.0 \%$ \\
\hline Economic/administrative & $24.3 \%$ & & $23.9 \%$ \\
\hline General (not specialized) & $20.3 \%$ & & $31.7 \%$ \\
\hline Services & $19.7 \%$ & & $39.4 \%$ \\
\hline \multicolumn{4}{|l|}{ Weekly working hours } \\
\hline \# Observations & $\mathrm{n}=4502$ & & $\mathrm{n}=3666$ \\
\hline Mean & 39.0 & & 31.0 \\
\hline (Standard deviation) & $(7.4)$ & & $(10.8)$ \\
\hline \multicolumn{4}{|l|}{ Hourly wage rates } \\
\hline \# Observations & $\mathrm{n}=4291$ & & $\mathrm{n}=3432$ \\
\hline Mean (Guilders) & 20.3 & & 16.5 \\
\hline (Standard deviation) & $(7.3)$ & & $(5.8)$ \\
\hline \multicolumn{4}{|l|}{ Age } \\
\hline Mean & 40.2 & & 38.0 \\
\hline (Standard deviation) & $(12.4)$ & & $(12.5)$ \\
\hline \multicolumn{4}{|l|}{ Household level variables } \\
\hline \multicolumn{4}{|l|}{ Non-labour income } \\
\hline \multicolumn{4}{|l|}{ Household level, weekly } \\
\hline Mean (guilders) & & 33.7 & \\
\hline \multicolumn{4}{|l|}{ Standard deviation } \\
\hline \multicolumn{4}{|l|}{ Employment status } \\
\hline Both partners working & & $62.9 \%$ & \\
\hline Husband working, wife not & & $20.5 \%$ & \\
\hline Wife working, husband not & & $6.3 \%$ & \\
\hline Both not working & & $10.3 \%$ & \\
\hline \multicolumn{4}{|l|}{ Marital status } \\
\hline Married & & $70.3 \%$ & \\
\hline
\end{tabular}


Table 2: Number of waves per household

\begin{tabular}{ccc}
\multicolumn{3}{c}{ (total \# of households: 1637) } \\
\hline \# Waves & \# Households & Frequency (\%) \\
\hline 1 & 404 & 24.7 \\
2 & 345 & 21.1 \\
3 & 270 & 16.5 \\
4 & 172 & 10.5 \\
5 & 135 & 8.3 \\
6 & 96 & 5.9 \\
7 & 77 & 4.7 \\
8 & 138 & 8.4 \\
\hline
\end{tabular}


Table 3: Simulated Maximum likelihood estimates Labour supply equations

\begin{tabular}{|c|c|c|c|c|}
\hline \multirow[b]{2}{*}{ Variable } & \multicolumn{2}{|c|}{ Husband } & \multicolumn{2}{|c|}{ Wife } \\
\hline & estimate & std. err. & estimate & std. err. \\
\hline intercept & $-12.4^{* *}$ & 5.6 & $22.9^{* *}$ & 5.6 \\
\hline wage husband & $2.5^{* *}$ & 0.1 & $0.30 * *$ & 0.07 \\
\hline wage wife & 0.14 & 0.09 & $1.5^{* *}$ & 0.4 \\
\hline$w_{m} /\left(w_{m}+w_{f}\right)$ & $21.7^{* *}$ & 8.0 & $-38.4^{* *}$ & 7.1 \\
\hline wage husband squared & $-0.041^{* *}$ & 0.002 & - & - \\
\hline wage wife squared & - & - & $-0.028^{* *}$ & 0.005 \\
\hline nonlabour income & $-0.0045^{* *}$ & 0.0017 & $-0.0051^{*}$ & 0.0027 \\
\hline log(age husb/17) & $28.9^{* *}$ & 5.5 & $21.2^{* *}$ & 9.0 \\
\hline $\log ($ age husb/17) squared & $-25.4^{* *}$ & 3.7 & $-14.1^{* *}$ & 5.7 \\
\hline $\log ($ age wife/17) & $-19.3^{* *}$ & 4.8 & $22.3^{* *}$ & 9.1 \\
\hline $\log$ (age wife/17) squared & $16.8^{* *}$ & 3.2 & $-36.1^{* *}$ & 5.9 \\
\hline Educ level husb. 1 & -0.72 & 0.94 & $-7.7 * *$ & 1.3 \\
\hline Educ level husb. 2 & $2.2^{* *}$ & 0.7 & -1.5 & 0.9 \\
\hline Educ level husb. 3 & $2.6^{* *}$ & 0.6 & -0.20 & 0.76 \\
\hline Educ level wife 1 & $1.6^{* *}$ & 0.8 & $-4.8^{* *}$ & 1.5 \\
\hline Educ level wife 2 & 0.84 & 0.58 & -1.1 & 1.3 \\
\hline Educ level wife 3 & $1.4^{* *}$ & 0.5 & -0.11 & 0.98 \\
\hline married & $1.0^{* *}$ & 0.4 & $-1.8^{* *}$ & 0.8 \\
\hline$s$ & $36.5^{* *}$ & 3.4 & - & - \\
\hline$S$ & - & - & -0.023 & 0.030 \\
\hline
\end{tabular}


Table 4: Parameters individual labour supply

\begin{tabular}{lrrrr}
\hline \multirow{2}{*}{ Variable } & \multicolumn{2}{c}{ Husband } & \multicolumn{2}{c}{ Wife } \\
\hline Non-lab. inc $\left(\alpha_{2}^{j}\right)$ & $-0.0074^{* *}$ & 0.0019 & $-0.013^{* *}$ & 0.004 \\
& & & & \\
(Own) Wage $\left(\alpha_{3}^{j}\right)$ & $2.7^{* *}$ & 0.1 & $1.7^{* *}$ & 0.4 \\
& & & & \\
(Own) wage squared $\left(\alpha_{4}^{j}\right)$ & $-0.041^{* *}$ & 0.002 & $-0.028^{* *}$ & 0.005 \\
& & & & \\
\hline **: significant at $5 \%$ level, *: $10 \%$ level & & & \\
\hline
\end{tabular}

Table 5 The parameters of the Sharing rule:

\begin{tabular}{lrr}
\hline variable & estimate & std. err. \\
\hline wage husband & $23^{* *}$ & 8 \\
wage wife & $-20^{*}$ & 11 \\
$w_{m} /\left(w_{m}+w_{f}\right)$ & $-2946^{* *}$ & 932 \\
nonlabour income & $0.61^{* *}$ & 0.21 \\
\hline
\end{tabular}

Table 6: The Sharing rule outside the participation frontier:

\begin{tabular}{|c|c|c|c|c|}
\hline \multirow[b]{2}{*}{ variable } & \multicolumn{2}{|c|}{$\begin{array}{c}\text { Husband works } \\
\text { Wife not }\end{array}$} & \multicolumn{2}{|c|}{$\begin{array}{l}\text { Wife works } \\
\text { Husband not }\end{array}$} \\
\hline & estimate & std. err. & estimate & std. err. \\
\hline wage husband & $-1444^{*}$ & 844 & $18^{*}$ & 11 \\
\hline wage wife & $-7428 * *$ & 3200 & $-20^{*}$ & 11 \\
\hline$w_{m} /\left(w_{m}+w_{f}\right)$ & $187450^{*}$ & 103555 & $-2984^{* *}$ & 947 \\
\hline nonlabour income & $26.0^{*}$ & 15.1 & 0.62 & 0.21 \\
\hline$r$ & -4962 & 1959 & - & - \\
\hline$R$ & - & - & -1.8 & 2.5 \\
\hline
\end{tabular}


Table 7: SSML estimates of the Wage equations

\begin{tabular}{|c|c|c|c|c|}
\hline \multirow[b]{2}{*}{ Variable } & \multicolumn{2}{|c|}{ Husband } & \multicolumn{2}{|c|}{ Wife } \\
\hline & estimate & std. err. & estimate & std. err. \\
\hline intercept & $3.1^{* *}$ & 0.05 & $2.3^{* *}$ & 0.04 \\
\hline log(age/17) & $-0.41^{* *}$ & 0.12 & $1.4^{* *}$ & 0.1 \\
\hline log(age/17) squared & $0.70^{* *}$ & 0.08 & $-0.75^{* *}$ & 0.08 \\
\hline Education level 1 & -0.05 & 0.03 & $-0.34^{* *}$ & 0.03 \\
\hline Education level 2 & $-0.25^{* *}$ & 0.02 & $-0.29 * *$ & 0.03 \\
\hline Education level 3 & $-0.25^{* *}$ & 0.02 & $-0.20 * *$ & 0.02 \\
\hline Education level 4 & $-0.11^{* *}$ & 0.02 & $-0.07 * *$ & 0.03 \\
\hline Technical & 0.019 & 0.014 & 0.003 & 0.028 \\
\hline Econ./adm. & $0.060 * *$ & 0.014 & $0.079^{* *}$ & 0.016 \\
\hline General & 0.018 & 0.016 & $0.062^{* *}$ & 0.016 \\
\hline 1991 & -0.002 & 0.020 & 0.035 & 0.025 \\
\hline 1992 & 0.008 & 0.019 & $0.055^{* *}$ & 0.025 \\
\hline 1993 & 0.00030 & .0195 & $0.083^{* *}$ & 0.024 \\
\hline 1994 & $0.060^{* *}$ & 0.018 & $0.052^{* *}$ & 0.023 \\
\hline 1995 & $0.064^{* *}$ & 0.018 & $0.090^{* *}$ & 0.024 \\
\hline 1996 & $0.062^{* *}$ & 0.018 & $0.11^{* *}$ & 0.02 \\
\hline 1997 & $0.089^{* *}$ & 0.019 & $0.15^{* *}$ & 0.03 \\
\hline
\end{tabular}


Table 8: SSML Estimates of the covariance matrix

\begin{tabular}{lcc}
\hline Parameter & estimate & std. err \\
\hline$\sigma_{m}$ & $15.2^{* *}$ & 0.6 \\
$\sigma_{f}$ & $17.4^{* *}$ & 0.4 \\
$\sigma_{m f}$ & $-74.5^{* *}$ & 3.8 \\
$\tau_{m}$ & $0.47^{* *}$ & 0.01 \\
$\tau_{f}$ & $0.32^{* *}$ & 0.002 \\
$\rho_{\tau}$ & $0.047^{* *}$ & 0.014 \\
$\sigma_{m u} / \tau_{m}$ & $-12.1^{* *}$ & 0.8 \\
$\sigma_{f u} / \tau_{f}$ & $-5.0^{* *}$ & 1.0 \\
\hline
\end{tabular}


Table 9: The random effects model

Labour supply equations

\begin{tabular}{|c|c|c|c|c|}
\hline \multirow[b]{2}{*}{ Variable } & \multicolumn{2}{|c|}{ Husband } & \multicolumn{2}{|c|}{ Wife } \\
\hline & estimate & std. err. & estimate & std. err. \\
\hline intercept & $21.7^{* *}$ & 2.9 & $10.8^{* *}$ & 3.6 \\
\hline wage husband & 0.05 & 0.12 & $0.11^{* *}$ & 0.05 \\
\hline wage wife & $0.35^{* *}$ & 0.07 & $1.5^{* *}$ & 0.2 \\
\hline$w_{m} /\left(w_{m}+w_{f}\right)$ & $11.6^{* *}$ & 5.1 & $-15.5^{* *}$ & 5.1 \\
\hline wage husband squared & $-0.014^{* *}$ & 0.001 & - & - \\
\hline wage wife squared & - & - & $-0.026^{* *}$ & 0.003 \\
\hline nonlabour income & $-0.011^{* *}$ & 0.002 & -0.0002 & 0.0019 \\
\hline $\log ($ age husb/17) & $47.1^{* *}$ & 5.6 & $26.5^{* *}$ & 6.4 \\
\hline $\log ($ age husb/17) squared & $-26.2^{* *}$ & 3.4 & $-19.3^{* *}$ & 4.2 \\
\hline $\log ($ age wife/17) & $-25.3^{* *}$ & 4.9 & $21.4^{* *}$ & 6.3 \\
\hline $\log$ (age wife/17) squared & $18.9^{* *}$ & 3.2 & $-28.8^{* *}$ & 4.2 \\
\hline Educ level husb. 1 & $-4.7 * *$ & 0.7 & $-6.8^{* *}$ & 0.9 \\
\hline Educ level husb. 2 & $-3.5^{* *}$ & 0.5 & -0.30 & 0.66 \\
\hline Educ level husb. 3 & $-2.1^{* *}$ & 0.4 & -0.52 & 0.53 \\
\hline Educ level wife 1 & -0.18 & 0.68 & $-4.0 * *$ & 0.9 \\
\hline Educ level wife 2 & 0.34 & 0.49 & -0.47 & 0.69 \\
\hline Educ level wife 3 & $1.5^{* *}$ & 0.4 & -0.13 & 0.58 \\
\hline married & $1.4^{* *}$ & 0.4 & $-1.7^{* *}$ & 0.5 \\
\hline$s$ & $52.6^{* *}$ & 5.9 & - & - \\
\hline$S$ & - & - & -0.018 & 0.027 \\
\hline
\end{tabular}


Table 10: Parameters of individual labour supply

The random effects model

\begin{tabular}{lrrrr}
\hline \multirow{2}{*}{ Variable } & \multicolumn{2}{c}{ Husband } & \multicolumn{2}{c}{ Wife } \\
\hline Non-lab. inc $\left(\alpha_{2}^{j}\right)$ & $-0.011^{* *}$ & 0.002 & $-0.015^{* *}$ & 0.007 \\
& & & & \\
(Own) Wage $\left(\alpha_{3}^{j}\right)$ & 0.13 & 0.10 & $1.9^{* *}$ & 0.3 \\
(Own) wage squared $\left(\alpha_{4}^{j}\right)$ & $-0.014^{* *}$ & 0.001 & $-0.026^{* *}$ & 0.003 \\
& & & & \\
\hline$* *:$ significant at 5\% level, *: $10 \%$ level & & \\
\hline
\end{tabular}

Table 11 The parameters of the Sharing rule: The random effects model

\begin{tabular}{lrr}
\hline variable & estimate & std. err. \\
\hline wage husband & $7^{*}$ & 4 \\
wage wife & $-32^{* *}$ & 8 \\
$w_{m} /\left(w_{m}+w_{f}\right)$ & $-1039^{* *}$ & 482 \\
nonlabour income & $0.99^{* *}$ & 0.13 \\
\hline
\end{tabular}

Table 12: The Sharing rule outside the participation frontier: The random effects model

\begin{tabular}{|c|c|c|c|c|}
\hline \multirow[b]{2}{*}{ variable } & \multicolumn{2}{|c|}{$\begin{array}{c}\text { Husband works } \\
\text { Wife not }\end{array}$} & \multicolumn{2}{|c|}{$\begin{array}{l}\text { Wife works } \\
\text { Husband not }\end{array}$} \\
\hline & estimate & std. err. & estimate & std. err. \\
\hline wage husband & -491 & 562 & $7^{*}$ & 4 \\
\hline wage wife & -6902 & 4562 & $-32^{* *}$ & 8 \\
\hline$w_{m} /\left(w_{m}+w_{f}\right)$ & 72042 & 74781 & $-1053^{* *}$ & 492 \\
\hline nonlabour income & 1.8 & 8.8 & $1.0 * *$ & 0.13 \\
\hline$r$ & -4711 & 3318 & - & - \\
\hline$R$ & - & - & -1.2 & 2.1 \\
\hline
\end{tabular}


Table 13: SSML estimates of the Wage equations

The random effects model

\begin{tabular}{|c|c|c|c|c|}
\hline \multirow[b]{2}{*}{ Variable } & \multicolumn{2}{|c|}{ Husband } & \multicolumn{2}{|c|}{ Wife } \\
\hline & estimate & std. err. & estimate & std. err. \\
\hline intercept & $3.0^{* *}$ & 0.04 & $2.2^{* *}$ & 0.04 \\
\hline $\log ($ age/17) & -0.12 & 0.11 & $1.5^{* *}$ & 0.1 \\
\hline log(age/17) squared & $0.52^{* *}$ & 0.07 & $-0.85^{* *}$ & 0.07 \\
\hline Education level 1 & $-0.20^{* *}$ & 0.04 & $-0.25^{* *}$ & 0.03 \\
\hline Education level 2 & $-0.35^{* *}$ & 0.02 & $-0.22^{* *}$ & 0.02 \\
\hline Education level 3 & $-0.26^{* *}$ & 0.02 & $-0.14^{* *}$ & 0.02 \\
\hline Education level 4 & $-0.15^{* *}$ & 0.02 & -0.02 & 0.02 \\
\hline Technical & $0.035^{* *}$ & 0.016 & $-0.055^{*}$ & 0.029 \\
\hline Econ./adm. & $0.088^{* *}$ & 0.017 & $0.048^{* *}$ & 0.013 \\
\hline General & 0.016 & 0.019 & $0.039 * *$ & 0.014 \\
\hline 1992 & 0.02 & 0.02 & $0.04^{*}$ & 0.02 \\
\hline 1993 & $0.04^{*}$ & 0.02 & $0.08^{* *}$ & 0.02 \\
\hline 1994 & $0.06^{* *}$ & 0.02 & $0.06^{* *}$ & 0.02 \\
\hline 1995 & $0.07^{* *}$ & 0.02 & $0.10^{* *}$ & 0.02 \\
\hline 1996 & $0.07^{* *}$ & 0.02 & $0.13^{* *}$ & 0.02 \\
\hline 1997 & $0.09^{* *}$ & 0.02 & $0.18^{* *}$ & 0.02 \\
\hline
\end{tabular}


Table 14: SSML Estimates of the covariance matrices The random effects model

\begin{tabular}{|c|c|c|}
\hline Parameter & estimate & std. err \\
\hline$\sigma_{m}$ & $7.8^{* *}$ & 0.1 \\
\hline$\sigma_{f}$ & $12.7^{* *}$ & 0.2 \\
\hline$\sigma_{m f}$ & $-34.0^{* *}$ & 1.9 \\
\hline$\tau_{m}$ & $0.31^{* *}$ & 0.003 \\
\hline$\tau_{f}$ & $0.27^{* *}$ & 0.002 \\
\hline$\rho_{\tau}$ & $0.15^{* *}$ & 0.01 \\
\hline$\sigma_{m u} / \tau_{m}$ & $-2.7^{* *}$ & 0.2 \\
\hline$\sigma_{f u} / \tau_{f}$ & $-4.3^{* *}$ & 0.5 \\
\hline$\sigma_{\theta, m}^{2}$ & $15.7^{* *}$ & 0.2 \\
\hline$\rho_{\theta, m f}$ & $-0.24^{* *}$ & 0.05 \\
\hline$\sigma_{\theta, f}^{2}$ & $8.1^{* *}$ & 0.4 \\
\hline$\sigma_{\omega, m}^{2}$ & $0.26^{* *}$ & 0.01 \\
\hline$\rho_{\omega, m f}$ & $0.33^{* *}$ & 0.03 \\
\hline$\sigma_{\omega, f}^{2}$ & $0.31^{* *}$ & 0.01 \\
\hline$\rho_{\theta \omega, m}$ & $-0.45^{* *}$ & 0.02 \\
\hline$\rho_{\theta \omega, f m}$ & $-0.82^{* *}$ & 0.01 \\
\hline$\rho_{\theta \omega, m f}$ & $-0.34^{* *}$ & 0.04 \\
\hline$\rho_{\theta \omega, f}$ & $0.59^{* *}$ & 0.04 \\
\hline
\end{tabular}




\section{References}

Apps, P, and R. Rees (1988), Taxation and the household, Journal of Public Economics, Vol. 35, pp. 355-369.

Blundell, R, P.A. Chiappori, T. Magnac and C. Meghir (2001), Collective labor supply: heterogeneity and nonparticipation, working paper WP01/19, The Institute for Fiscal Studies, London.

Chiappori, P.A. (1988), Rational household labor supply, Econometrica, Vol. 56 , pp. 63-89.

Chiappori, P.A. (1992), Collective labor supply and welfare, Journal of Political Economy, Vol. 100, pp. 437-467.

Chiappori, P.A. (2002), Marriage market, divorce legislation, and household labor supply, Journal of Polictical Economy, Vol. 110, no. 1, pp. 37-72.

Donni, O (2003), Collective household labor supply: nonparticipation and income taxation, Journal of Public Economics, Vol. 87, pp. 1179-1198.

Fortin, B. and G. Lacroix (1997), A test of the unitary and collective models of household labor supply, Economic Journal, Vol. 107, pp. 933-955.

Hausman, J. and P. Ruud (1984), Family labor supply with taxes, American Economic Review, Vol. 74, pp. 242-248.

Heckman, J.J. (1974), Shadow prices, market wages and labor supply, Econometrica, Vol. 42, no. 4, pp. 679-694.

Heckman, J.J. (1978), Dummy endogenous variables in a simultaneous equation system, Econometrica, Vol. 46, pp. 931-960.

Kooreman, P. (1994), Estimation of econometric models of some discrete games, Journal of Applied Econometrics, Vol. 9, pp. 255-268.

Vermeulen, F. (2002), Collective Household Models: Principles and Main Results, forthcoming in Journal of Economic Surveys. 